\title{
External Balances, Trade and Financial Conditions
}

\author{
Martin D. D. Evans* \\ Department of Economics, Georgetown University.
}

February 2, 2016

\begin{abstract}
I present a new model for the U.S. external position that accounts for the accumulation of international debt over the past 60 years. The model is based on the present value restriction that links a country's external position to future trade flows and financial conditions in the absence of arbitrage opportunities and Ponzi schemes. It features the role played by the stochastic discount factor, the trade and valuation adjustment channels and provides a decomposition of the U.S. external position into secular and cyclical components. The model shows that shocks operating via the valuation channel are the dominant drivers of cyclical dynamics, accounting for approximately 80 percent of the variance over the 60 -year sample. This channel works primarily via capital gains and losses on U.S. foreign assets and is closely tied to the international value of the U.S. dollar. In contrast, there is no evidence that valuation channel adjustments contribute to the secular dynamics, but differences between the average returns on foreign assets and liabilities raise the steady-state debt-to-GDP ratio from approximately 12 to 15 percent. The long-term deterioration in the U.S. position represents a move towards the steady-state before the early 1990's and a move away from the steady-state thereafter. I quantify the expected improvement in future U.S. trade balances needed to justify this as a sustainable path and show that they are unprecedented in the last 60 years. I also study the behavior of the U.S. position during the 2007-8 financial crisis.
\end{abstract}

Keywords: Global Imbalances, External Positions, Current Accounts, Trade Flows, Valuation Effects, Stochastic Discount Factors, International Asset Pricing

JEL Codes: F31, F32, F34

*Email: evansmdd@gmail.com. Mailing Address: Department of Economics, Georgetown University, Washington D.C. 20057. 


\section{Introduction}

The past 60 years have witnessed a substantial worsening of the U.S. external position. Starting from net asset position of approximately 15 percent of GDP in the early 1950's, the accumulation of international debt produced a net liability position equal to 51 percent of GDP by the end of 2013. In light of this, the question of whether the prolonged deterioration in the U.S. external position represents an adjustment along a sustainable path or is a precursor to an abrupt change accompanied by a crisis has sparked much debate among researchers and policymakers. ${ }^{1}$ This paper brings new evidence to bear on this question by presenting a novel model for the U.S. external position that accounts for the accumulation of international debt over the past 60 years.

The model I develop is based on the present value restriction that links the value of a country's external position to future trade flows and financial conditions in the absence of arbitrage opportunities and Ponzi schemes. This restriction holds in a wide class of theoretical models and accommodates the fact that international investors can trade a wide variety of securities. The model contains several features that distinguish it from earlier work, notably by Gourinchas and Rey (2007a) (G\&R) and Corsetti and Konstantinou (2012) (C\&K). First, it features the stochastic discount factor (SDF) that determines the arbitrage-free prices of all freely traded securities. The proximate determinants of a country's external position are more simply expressed using the SDF rather than returns on foreign assets and liabilities (as in G\&R and C\&K) which facilitates the construction of the model. Second, the model distinguishes between the effects of shocks to the current SDF and trade flows and the effects of news concerning the future SDF and trade flows. This distinction is empirically important because news concerning the future SDF is a much more significant driver of the U.S. external position than shocks to the current SDF. Third, the model provides a decomposition of the external position along two dimensions: (i) it splits the dynamics into secular and cyclical components and (ii) allows for changes in the external position via the trade and valuation channels. This feature allows us to examine the factors driving the U.S. external position over a wide frequency range (from quarters to decades). In contrast, $G \& R$ examine how the trade and valuation channels contribute to cyclical variations in the U.S. external position while G\&R focus on how different shocks affect the current account (i.e., quarterly changes in the external position). Neither of these models explicitly focus on why there has been the persistent (low frequency) deterioration in the U.S. external position over past 60 years. Finally, the model estimates provide an insight into the forces driving the U.S.

\footnotetext{
${ }^{1}$ Contributors to the debate include: Blanchard and Giavazzi (2002), Summers (2004), Obstfeld and Rogoff (2005), Roubini and Setser (2005), Bernanke (2005), Hausmann and Sturzenegger (2006), Engel and Rogers (2006), Backus et al. (2009), Mendoza, Quadrini, and Rıs-Rull (2009), Durdu, Mendoza, and Terrones (2012) and Fogli and Perri (2015), among others.
} 
external position during the financial crisis of 2007-8, particularly the role of the U.S. as a global insurer (see, e.g., Gourinchas, Rey, and Govillot 2010).

The model estimates provide several sets of striking results. First, I find that shocks operating via the valuation channel are the dominant drivers of cyclical position dynamics, accounting for approximately 80 percent of the variance over the 60-year sample. In other words, changing expectations about future SDFs rather than future trade flows account for most of the short-term changes in the U.S. position. These findings indicate that the valuation channel is much more important empirically than the results in G\&R suggest. I also present novel results concerning asymmetry in valuation channel. It appears that the channel works primarily via capital gains and losses on U.S. foreign assets rather than liabilities and that this asymmetry is closely tied to changes in the international value of the U.S. dollar. The presence of this asymmetry is at odds with existing theoretical models of external adjustment (see, e.g., Pavlova and Rigobon, 2008, Tille and van Wincoop, 2010, Devereux and Sutherland, 2010, Coeurdacier and Rey, 2012, Gourinchas and Rey, 2013 and Evans, 2014).

Second, I find the differences between the returns on U.S. foreign assets and foreign liabilities affect the steady-state level of U.S. external debt, but do not contribute to the secular dynamics of the external position. Over the span of my data, average asset returns are slightly above average liability returns, consistent with the existence of a U.S. "Exorbitant Privilege" (G\&R). I estimate that the Exorbitant Privilege increases the steady-state debt-to-GDP ratio from approximately 12 to 15 percent. At the same time, there is no evidence that valuation channel adjustments significantly contribute to the secular dynamics of the U.S. position. Variations in the SDF are insufficiently persistent to make any significant contribution to the secular deterioration of the U.S. external position. This finding runs contrary to recent research that focuses on asymmetric financial development as a driver of external imbalances (see, e.g., Caballero, Farhi, and Gourinchas, 2008 and Gourinchas and Rey, 2013).

My model estimates show that the long-term deterioration in the U.S. external position over the past 60 years represents a move towards the steady-state before the early 1990's and a move away from the steady-state thereafter. These secular movements can be interpreted as part of a sustainable external adjustment process, but only under very exacting conditions. In particular, the model quantifies the expected improvement in future U.S. trade balances needed to justify the historical deterioration in the external position as sustainable. These expectations are without precedence in the 60-year span of my data. In other words, it is impossible to view the long-term evolution of the U.S. external position as a sustainable adjustment process unless we believe that agents have been consistently overoptimistic about future improvements in the trade balance. 
This finding is reminiscent of Engel and Rogers (2006) who argued that the deterioration in the U.S. current account between 1998 and 2004 could be attributed to forecasts of rising U.S. growth relative to other advanced countries. The crucial difference here is that I focus on the secular deterioration in the U.S. external position lasting many decades.

Finally, I use the model to provide a historical perspective on external adjustment via the valuation and trade channels after 1980. In so doing I provide an empirical perspective on the role played by the global savings glut (Bernanke, 2005), safe-haven portfolio shifts and changes in the U.S. term structure, before and during the 2007-8 financial crisis. This analysis reveals a strong association between the real effective dollar exchange rate and the valuation channel. It also identifies the degree to which the U.S. acted as the global provider of insurance during the height of the crisis. Between 2008:I and 2009:II I estimate that the U.S. made an "insurance payment" to the rest of the world equal to approximately 30 percent of GDP.

The remainder of the paper is organized as follows. Section 1 derives the present value restriction on the external position implied by the absence of arbitrage opportunities and Ponzi schemes. Section 2 develops the model from this restriction. I describe the data and the model estimates in Sections 3 and 4 . Sections 5 and 6 analyze the model estimates. Section 7 concludes. $^{2}$

\section{Valuation of External Positions}

In this section, I first develop the nonlinear present value restriction on a country's Net Foreign Liability (NFL) position implied by the absence of Ponzi schemes and arbitrage opportunities. I then derive an approximate form of the restriction that serves as the foundation of the model.

\subsection{Debt, Returns and Trade Flows}

The starting point is the country's consolidated budget constraint:

$$
F L_{t+1}-F A_{t+1}=M_{t+1}-X_{t+1}+R_{t+1}^{\mathrm{FL}} F L_{t}-R_{t+1}^{\mathrm{FA}} F A_{t} .
$$

Here $F A_{t+1}$ and $F L_{t+1}$ denote the value of foreign assets and liabilities of the country at the end of perior $t+1$, while $X_{t+1}$ and $M_{t+1}$ represent the flow of exports and imports during period $t+1$, all measured in real terms. The gross real return on the foreign asset and liability portfolios between the end of periods $t$ and $t+1$ are denoted by $R_{t+1}^{\mathrm{FA}}$ and $R_{t+1}^{\mathrm{FL}}$, respectively.

In a world where financial assets with the same payoffs have the same prices and there are no restrictions on the construction of portfolios (such as short sales constraints), there exists a

\footnotetext{
${ }^{2}$ Supplementary information on the data, estimation methods, and results are available in a separate Appendix.
} 
stochastic discount factor $(\mathrm{SDF}) \mathcal{K}_{t+1}$, such that $1=\mathbb{E}_{t}\left[\mathcal{K}_{t+1} R_{t+1}^{i}\right]$, where $R_{t+1}^{i}$ is the (gross real) return on any freely traded asset $i$, and $\mathbb{E}_{t}[$.] denotes expectations conditioned on agents' common period- $t$ information. ${ }^{3}$ I assume that this no-arbitrage condition applies to the returns on every security in the country's asset and liability portfolios, and so it also applies to the returns on the portfolios themselves; i.e.

$$
1=\mathbb{E}_{t}\left[\mathcal{K}_{t+1} R_{t+1}^{\mathrm{FA}}\right] \quad \text { and } \quad 1=\mathbb{E}_{t}\left[\mathcal{K}_{t+1} R_{t+1}^{\mathrm{FL}}\right]
$$

These restrictions are present in a very large class of international macro models including, for example, many in the new Open Economy Financial Macroeconomics literature surveyed by Coeurdacier and Rey (2012). As such, I view (2) as a useful set of minimal theoretical restrictions to impose on the empirical model. ${ }^{4}$

Equations (1) and (2) allow us to derive a simple expression for the county's international debt position, as measured by the value of net foreign liabilities, $N F L_{t}=F L_{t}-F A_{t}$. Multiplying both sides of (1) by the SDF, taking conditional expectations and applying the restrictions in (2) gives

$$
\begin{aligned}
\mathbb{E}_{t}\left[\mathcal{K}_{t+1} N F L_{t+1}\right] & =\mathbb{E}_{t}\left[\mathcal{K}_{t+1}\left(M_{t+1}-X_{t+1}\right)\right]+\mathbb{E}_{t}\left[\mathcal{K}_{t+1} R_{t+1}^{\mathrm{FL}}\right] F L_{t}-\mathbb{E}_{t}\left[\mathcal{K}_{t+1} R_{t+1}^{\mathrm{FA}}\right] F A_{t} \\
& =\mathbb{E}_{t}\left[\mathcal{K}_{t+1}\left(M_{t+1}-X_{t+1}\right)\right]+N F L_{t} .
\end{aligned}
$$

Rearranging this expression and solving forward using the law of iterated expectations we obtain

$$
N F L_{t}=\mathbb{E}_{t} \sum_{i=1}^{\infty} \mathcal{K}_{t+i}^{(i)}\left(X_{t+i}-M_{t+i}\right)+\mathbb{E}_{t} \lim _{i \rightarrow \infty} \mathcal{K}_{t+i}^{(i)} N F L_{t+i}
$$

where $\mathcal{K}_{t+i}^{(i)}=\prod_{j=1}^{i} \mathcal{K}_{t+j}$ is the $i$-period ahead discount factor (with $\mathcal{K}_{t+1}^{(1)}=\mathcal{K}_{t+1}$ ). The last term on the right identifies the expected present value of the country's international debt position as the horizon rises without limit using a discount factor determined by the SDF. To rule out Ponzi

\footnotetext{
${ }^{3}$ This condition is very general. It does not rely on agents' preferences, the rationality of their expectations, or the completeness of financial markets (see Cochrane, 2001 and Evans, 2011 for textbook discussions).

${ }^{4}$ An alternative approach would be to replace (2) with restrictions on returns implied by a structural model that accommodates real-world financial frictions; such as short sales constraints, capital controls, borrowing restrictions, tax, and other transaction costs. I leave such a complex undertaking to future work.
} 
schemes, I assume that $\mathbb{E}_{t} \lim _{i \rightarrow \infty} \mathcal{K}_{t+i}^{(i)} N F L_{t+i}=0,{ }^{5}$ so (4) becomes

$$
N F L_{t}=\mathbb{E}_{t} \sum_{i=1}^{\infty} \mathcal{K}_{t+i}^{(i)}\left(X_{t+i}-M_{t+i}\right)
$$

This equation is similar to one derived in Obstfeld (2012). It states that the country's NFL position at the end of period $t$ must equal the expected present discounted value of future trade surpluses, discounted at the cumulated SDF. ${ }^{6}$ As such, it describes the link between a country's international debt position and the prospects for future trade flows and financial conditions. Note, also, that the expected future trade flows and SDFs on the right-hand-side of (5) represent the proximate determinants of the NFL position. More fundamental factors, such as demographic trends or asymmetries in financial development across countries, can only affect the NFL position insofar as they impact on these expectations.

Equation (5) provides an exact closed-form expression for the country's NFL position in terms of other variables. In general, it is impossible to derive such an expression without the no arbitrage conditions in (2). To see why, consider the following expression derived (by iterating forward and taking expectations) from the consolidated budget alone:

$$
N F L_{t}=\mathbb{E}_{t} \sum_{i=1}^{\infty}\left(\prod_{j=1}^{i} R_{t+j}^{\mathrm{NFL}}\right)^{-1}\left(X_{t+i}-M_{t+i}\right)+\mathbb{E}_{t} \lim _{i \rightarrow \infty}\left(\prod_{j=1}^{i} R_{t+j}^{\mathrm{NFL}}\right)^{-1} N F L_{t+i}
$$

where $R_{t+1}^{\mathrm{NFL}}=\frac{F L_{t}}{N F L_{t}} R_{t+1}^{\mathrm{FL}}-\frac{F A_{t}}{N F L_{t}} R_{t+1}^{\mathrm{FA}}$. The key difference between this equation and (4) is that that the right-hand-side includes the future returns on net foreign liabilities, $R_{t+i}^{\mathrm{NFL}}$, instead of the SDF. If returns on assets and liabilities are equal, the return on net foreign liabilities simplifies to $R_{t+i}^{\mathrm{NFL}}=R_{t+i}^{\mathrm{FL}}=R_{t+i}^{\mathrm{FA}}$, so the first term on the right-hand side involves future trade flows and returns. In this special case we can determine the country's NFL position (absent Ponzi schemes), from the first term on the right-hand side of (6) without reference to the SDF. Unfortunately, the simplicity of this approach does not carry over to the empirically relevant case where the

\footnotetext{
${ }^{5}$ For intuition, suppose a debtor country decides to simply roll over existing asset and liability positions while running zero future trade balances. The country's asset and liability portfolios would then evolve as $F A_{t+i}=R_{t+i}^{\mathrm{FA}} F A_{t+i-1}$ and $F L_{t+i}=R_{t+i}^{\mathrm{FL}} F L_{t+i-1}$ for all $i>0$. (3) implies that the value of a claim to the country's debt next period is just $\mathbb{E}_{t}\left[\mathcal{K}_{t+1} N F L_{t+1}\right]=\mathbb{E}_{t}\left[\mathcal{K}_{t+1}\left(M_{t+1}-X_{t+1}\right)\right]+N F L_{t}=N F L_{t}$. This same reasoning applies in all future periods, so the value of a claim to the debt $\tau$ periods ahead is $\mathbb{E}_{t}\left[\mathcal{K}_{t+\tau}^{(\tau)} N F L_{t+\tau}\right]=\mathbb{E}_{t}\left[\mathcal{K}_{t+\tau-1}^{(\tau-1)} \mathbb{E}_{\tau-1}\left[\mathcal{K}_{t+\tau} N F L_{t+\tau}\right]\right]=. .=N F L_{t}$. Taking the limit as $\tau \rightarrow \infty$ gives $N F L_{t}=\mathbb{E}_{t} \lim _{i \rightarrow \infty}\left[\mathcal{K}_{t+i}^{(i)} N F L_{t+i}\right]>0$. Thus, the country's current debt position must be equal to the value of a claim on rolling the asset and liability positions forward indefinitely into the future. Clearly then, no country can initiate a Ponzi scheme when $\mathbb{E}_{t} \lim _{i \rightarrow \infty} \mathcal{K}_{t+i}^{(i)} N F L_{t+i} \leq 0$. Moreover, since NFL positions must aggregate to zero across countries (by market clearing), if $\mathbb{E}_{t} \lim _{i \rightarrow \infty} \mathcal{K}_{t+i}^{(i)} N F L_{t+i}>0$ at least one other country must be involved in a Ponzi scheme. The restriction thus prevents any country from adopting a Ponzi scheme.

${ }^{6}$ Notice that this end-of-period value incorporates the effects of period- $t$ trade flows, and the returns on pre-existing asset and liability holdings: i.e., $M_{t}-X_{t}+R_{t}^{\mathrm{FL}} F L_{t-1}-R_{t}^{\mathrm{FA}} F A_{t-1}$ from equation (1).
} 
returns on assets and liabilities differ. Now future returns on net foreign liabilities, $R_{t+i}^{\mathrm{NFL}}$, depend of future foreign asset and liability holdings, so the right-hand-side of (4) involves expectations of future holdings as well as trade flows and returns. As such, (6) does not provide us with a closed-form expression for the country's NFL position in terms of other variables (even when the no-Ponzi condition eliminates the last term). ${ }^{7}$

There are several other aspects of equation (5) worth noting. First, it holds whatever the composition of the country's asset and liability portfolios (i.e. whatever the fractions held in equity, bonds, etc.), and however those fractions are determined (by optimal portfolio choice or some other method). ${ }^{8}$ Second, equation (5) takes explicit account of risk. A country's NFL position is equal to the value of a claim to the future stream of trade surpluses in a world where those surpluses are uncertain. This is not the same a discounting future trade surpluses by the expected path of the risk-free rate. Equation (5) also pins down the current account, $C A_{t}=-\Delta N F L_{t}$, where $\Delta$ denotes the first-difference operator. In particular, the appendix shows that combining this definition with (5) produces

$$
\begin{aligned}
C A_{t}=\mathbb{E}_{t-1} & \left\{\mathcal{K}_{t}\left(X_{t}-M_{t}\right)-\left(1-\mathcal{K}_{t}\right) \sum_{i=1}^{\infty} \mathcal{K}_{t+i}^{(i)}\left(X_{t-1+i}-M_{t-1+i}\right)\right\}\left(\mathbb{E}_{t-1} \mathcal{K}_{t}\right)^{-1} \\
+ & \mathbb{C V}_{t-1}\left(\mathcal{K}_{t}, N F L_{t}\right)\left(\mathbb{E}_{t-1} \mathcal{K}_{t}\right)^{-1}-\left(\mathbb{E}_{t}-\mathbb{E}_{t-1}\right) \sum_{i=1}^{\infty} \mathcal{K}_{t+i}^{(i)}\left(X_{t+i}-M_{t+i}\right),
\end{aligned}
$$

The first term on the right-hand-side shows how the anticipated difference between the current trade balance and the discounted present value of future trade balances drives the predictable component of the current account. This terms shows the degree to which anticipated future trade deficits produce current account surpluses needed to keep the country's NFL position on a sustainable path. The second term identifies a hedging component. Equation (5) implies that, ceteris paribus, a positive covariance between the SDF and NFL position, $\mathbb{C V}_{t-1}\left(\mathcal{K}_{t}, N F L_{t}\right)$ adds to $N F L_{t-1}$. Intuitively, the holders of a country's (net) debt need to be compensated for the risk of an unanticipated capital loss (i.e., a fall in $N F L_{t}$ ) when their marginal utility is high (i.e., when $\mathcal{K}_{t}$ is low). This hedging effect adds to the current account by lowering $\mathbb{E}_{t-1} \Delta N F L_{t}$. The third term identifies the affects of news that changes expectations about future trade flows and/or the SDF. In a world of certainty with a constant SDF, the second and third terms

\footnotetext{
${ }^{7}$ To be clear, in an equilibrium without Ponzi schemes and arbitrage opportunities the country's NFL position satisfies both (5) and (6), so my choice to use (5) as the foundation for the empirical model is purely practical.

${ }^{8}$ To see why, note that $R_{t+1}^{\mathrm{F}}=\sum_{j} \alpha_{j, t} R_{t+1}^{\mathrm{F} j}$ where $R_{t+1}^{\mathrm{F}_{j}}$ denotes the return on $\mathrm{F}=\{\mathrm{FA}$, FL $\}$ (asset or liability) security $j$ and $\alpha_{j, t}$ are the ex-ante portfolio shares (determined in period $t$ ) with $\sum_{j} \alpha_{j, t}=1$. As long as the no-arbitrage condition applies to the returns on the individual securities, then $\mathbb{E}_{t}\left[\mathcal{K}_{t+1} R_{n, t+1}^{\mathrm{F}}\right]=$ $\mathbb{E}_{t}\left[\sum_{j} \alpha_{j, t} \mathcal{K}_{t+1} R_{t+1}^{\mathrm{F} j}\right]=\sum_{j} \alpha_{j, t} \mathbb{E}_{t}\left[\mathcal{K}_{t+1} R_{t+1}^{\mathrm{F}_{j}}\right]=1$ for $\mathrm{F}=\{\mathrm{FA}, \mathrm{FL}\}$ and any set of portfolio shares $\alpha_{j, t}$.
} 
disappear leaving $C A_{t}=\left(X_{t}-M_{t}\right)-(1-\mathcal{K}) \sum_{i=0}^{\infty} \mathcal{K}^{i}\left(X_{t+i}-M_{t+i}\right)$. Under these circumstance the current account is solely determined by the difference between the current trade balance and its permanent level - a the key element in the international approach to the current account (see, e.g., Gourinchas and Rey, 2013). Obviously, equation (7) is far more complex than (5), so the empirical model I develop focuses on the NFL position rather than the current account.

\subsection{Scaling}

It is common to consider the ratio of a country's external position to another variable, typically GDP. This form of scaling is easily accommodated by equation (5). Dividing both sides by the scaling variable $\mathcal{Z}_{t}$ and simplifying gives

$$
\frac{N F L_{t}}{\mathcal{Z}_{t}}=\mathbb{E}_{t} \sum_{i=1}^{\infty}\left\{\prod_{j=1}^{i}\left[\mathcal{K}_{t+j}\left(\frac{\mathcal{Z}_{t+j}}{\mathcal{Z}_{t+j-1}}\right)\right]\right\}\left(\frac{X_{t+i}-M_{t+i}}{\mathcal{Z}_{t+i}}\right)
$$

Here the country's relative NFL position is determined by the expected present discounted value of relative trade surpluses with a discount factor that is adjusted to account for future growth in the scaling variable.

Although GDP is often used as a scaling variable, it is not the most convenient choice when developing a model for the U.S. position. To see why, Panels A and B of Figure 1 plot the $N F L_{t} / \mathcal{Z}_{t}$ series using GDP, $\mathcal{Y}_{t}$, and a measure of total trade, $\mathcal{T}_{t}=X_{t}^{1 / 2} M_{t}^{1 / 2}$, as scaling variables. These plots show that the $N F L_{t} / \mathcal{Y}_{t}$ trend is relatively stable until the early 1980's, but thereafter it moves upward at a higher rate. In contrast the upward trend in $N F L_{t} / \mathcal{T}_{t}$ appears stable over the entire sample period. Since it is easier to build a model based on (8) that accounts for the steady trend in $N F L_{t} / \mathcal{T}_{t}$ rather than the varying trend in $N F L_{t} / \mathcal{Y}_{t}$, I use total trade as the scaling variable. With this choice (8) becomes

$$
\frac{N F L_{t}}{\mathcal{T}_{t}}=\mathbb{E}_{t} \sum_{i=1}^{\infty} \exp \left(\sum_{j=1}^{i} \kappa_{t+j}+\Delta \tau_{t+j}\right)\left\{\left(N X_{t+i}\right)^{1 / 2}-\left(N X_{t+i}\right)^{-1 / 2}\right\}
$$

where $\kappa_{t}=\ln \mathcal{K}_{t}, \Delta \tau_{t}=\ln \left(\mathcal{T}_{t} / \mathcal{T}_{t-1}\right)$ and $N X_{t}=X_{t} / M_{t}$ 
Figure 1: Scaling By GDP and Trade

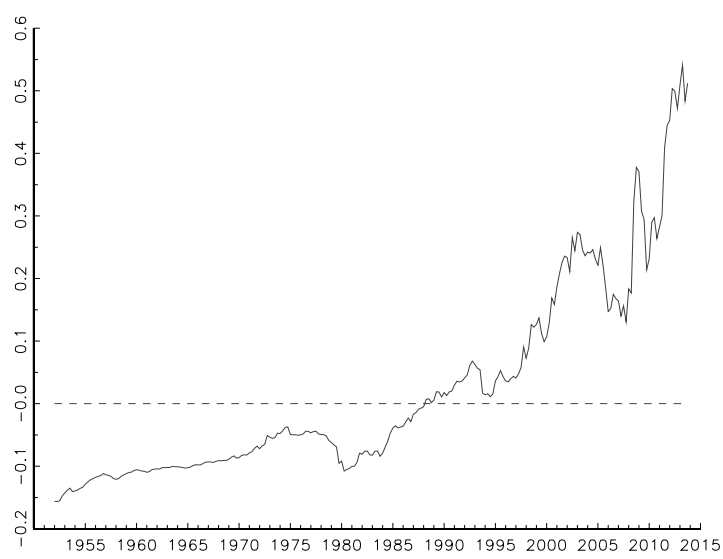

A: $N F L_{t} / \mathcal{Y}_{t}$

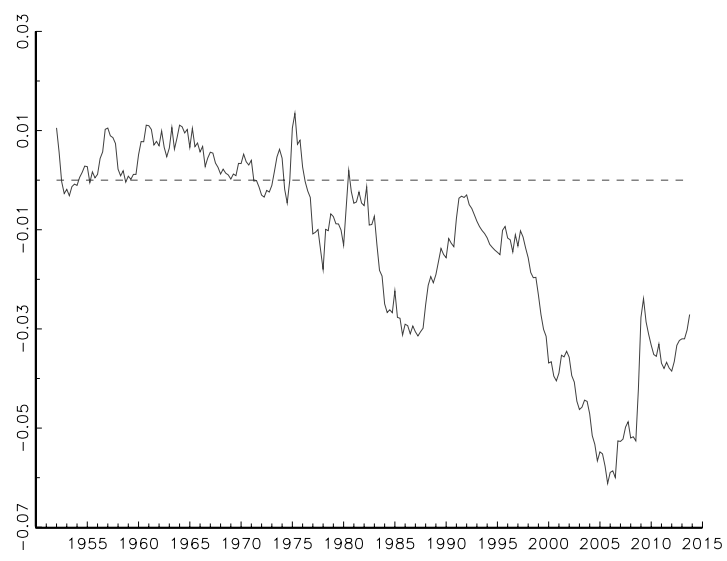

$\mathrm{C}:\left(X_{t}-M_{t}\right) / \mathcal{Y}_{t}$

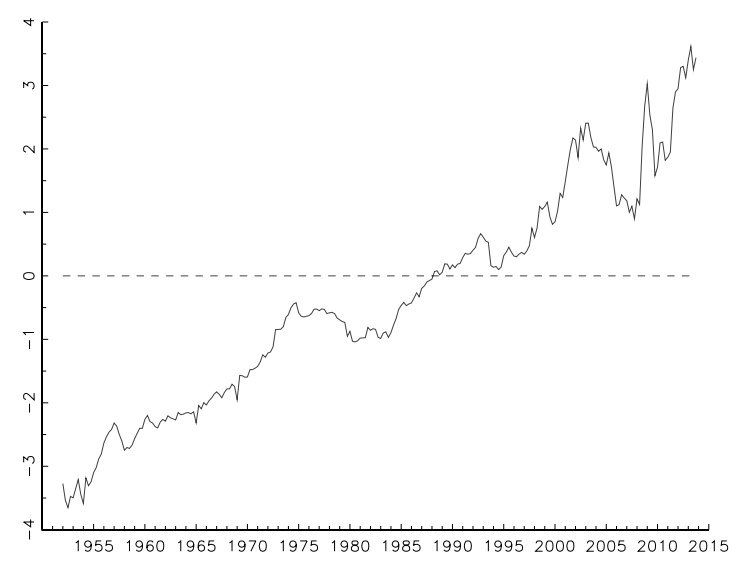

$\mathrm{B}: N F L_{t} / \mathcal{T}_{t}$

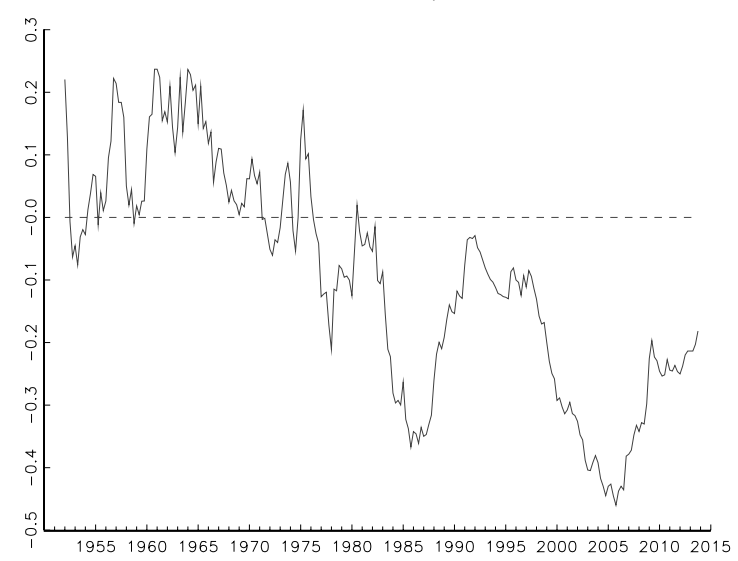

$\mathrm{D}: \ln \left(X_{t} / M_{t}\right)$

Panels $\mathrm{C}$ and D of Figure 1 compare the behavior of the $\log$ net export ratio, $\ln \left(N X_{t}\right)$, with that of the net export-to-GDP ratio, $\left(X_{t}-M_{t}\right) / \mathcal{Y}_{t}$. The plots show that these two series are strongly correlated; in fact the sample correlation is 0.96 . The model I develop below links movements in $N F L_{t} / \mathcal{T}_{t}$ to estimates of agents' expectations concerning the future path for $\ln \left(N X_{t}\right)$. These expectations are closely correlated with expectations about the future path for $\left(X_{t}-M_{t}\right) / \mathcal{Y}_{t}$

\subsection{Approximation}

While equation (9) provides the theoretical foundation for the model, the right-hand-side contains agents' expectations of nonlinear functions of several future variables which are hard to estimate. I, therefore, derive the model from an approximation based on three assumptions:

A1 The $\log \mathrm{SDF}, \kappa_{t}$, is a covariance stationary process with $\mathbb{E}\left[\kappa_{t}\right]=\kappa$. 
A2 The growth in trade, $\Delta \tau_{t}$, is a covariance stationary process with $\mathbb{E}\left[\Delta \tau_{t}\right]=g$, where $g<-\kappa$.

A3 The log net export ratio can be decomposed as $\ln \left(N X_{t}\right)=\overline{n x}_{t}+n x_{t}$, where $\overline{n x}_{t}$ is a secular component and $n x_{t}$ is a covariance stationary component with $\mathbb{E}\left[n x_{t}\right]=0$. Agents' expectations concerning the future path of the secular component are given by $\mathbb{E}_{t} \overline{n x}_{t+i}=$ $\lambda_{t}(i)$, where $\lambda_{t}($.$) is a deterministic function of t$ with $\lim _{i \rightarrow \infty} \lambda_{t}(i)=\lambda$, a constant.

Assumptions A1 and A2 are consistent with a wide range of theoretical models. For example, $\kappa_{t}$ is proportional to consumption growth in representative agent models with time-separable CRRA utility, so A1 would hold in such models when consumption growth is covariance stationary. More generally, estimates of the SDF implied by the behavior of returns (derived below) imply that $\kappa_{t}$ is covariance stationary. Assumption A2 allows for the presence of long-term growth in total trade; consistent with U.S. data (see Table 1). It also places an upper limit on the growth to ensure that future trade imbalances are discounted at a rate below one. My estimates of $g$ and $\kappa$ satisfy this restriction.

Assumption A3 links the behavior of the net export ratio over the sample with agents' expectations concerning its future path. Standard open economy models imply that the net export ratio follows a mean-zero covariance stationary process, but this implication is clearly at odds with the visual evidence in Figure 1. Assumption A3 allows the log net export ratio to contain a secular trend $\overline{n x_{t}}$ within the sample. I assume that agents' expectations about the secular trend evolve slowly through time, and their long-term expectations for the net export ratio are constant because $\lim _{i \rightarrow \infty} \mathbb{E}_{t} \ln N X_{t+i}=\lim _{i \rightarrow \infty}\left[\lambda_{t}(i)+\mathbb{E}_{t} n x_{t+i}\right]=\lambda$. This assumption embodies the idea that agents expect a change in the secular trend beyond the end of the sample. ${ }^{9}$

These assumptions allow for the presence of stochastic trends in the data but restrict how they affect log exports and imports. In particular, assumptions A2 and A3 imply that both variables share the same stochastic trend and are cointegrated one-to-one. Any permanent shock to the level of log exports must ultimately be reflected one-for-one in the level of log imports (otherwise $n x_{t}$ would be non-stationary), and also in the level of log trade because $\tau_{t} \equiv \ln \mathcal{T}_{t}=\frac{1}{2} \ln X_{t}+\frac{1}{2} \ln M_{t}$ by definition.

I approximate the right-hand-side of (9) around the point where $\kappa_{t}=\kappa, \Delta \tau_{t}=g$ and $N X_{t}=\exp (\lambda)=\Lambda$. This gives

$$
N F L_{t} / \mathcal{T}_{t}=\overline{n f l}_{t}+n f l_{t}
$$

where

\footnotetext{
${ }^{9}$ This assumption is very similar to the one made by $\mathrm{C} \& \mathrm{~K}$ that the trends in different variables converge beyond the end of the sample. Also, G\&R assume that the deterministic economy (used in their approximation) eventually settles into a balanced growth path.
} 


$$
\overline{n f l}_{t}=\eta \rho+\psi \sum_{i=1}^{\infty} \rho^{i}\left[\lambda_{t}(i)-\lambda\right]
$$

and

$$
n f l_{t}=\eta \mathbb{E}_{t} \sum_{i=1}^{\infty} \rho^{i}\left(\kappa_{t+i}-\kappa\right)+\eta \mathbb{E}_{t} \sum_{i=1}^{\infty} \rho^{i}\left(\Delta \tau_{t+i}-g\right)+\psi \mathbb{E}_{t} \sum_{i=1}^{\infty} \rho^{i} n x_{t+i}
$$

with $\rho=\exp (g+\kappa)<1, \eta=\frac{1}{1-\rho}\left(\Lambda^{1 / 2}-\Lambda^{-1 / 2}\right)$ and $\psi=\frac{1}{2}\left(\Lambda^{1 / 2}+\Lambda^{-1 / 2}\right)$. This approximation splits $N F L_{t} / \mathcal{T}_{t}$ into secular and cyclical components. The secular component is determined in (11) by agents' expectations concerning the secular trend in net exports, while the cyclical component is determined in (12) by agents' expectations concerning the future SDF, the growth in trade and the cyclical variations in net exports.

This approximation contains several noteworthy features. First, assumptions A1-A3 imply that $\lim _{i \rightarrow \infty} \mathbb{E}_{t} \overline{n f l}_{t+i}=\eta \rho$ and $\lim _{i \rightarrow \infty} \mathbb{E}_{t} n f l_{t+i}=0$, so agents' long-term expectations for $N F L_{t} / \mathcal{T}_{t}$ (i.e. $\left.\lim _{i \rightarrow \infty} \mathbb{E}_{t}\left[N F L_{t+i} / \mathcal{T}_{t+i}\right]\right)$ equal $\eta \rho=\frac{\rho}{1-\rho}\left(\Lambda^{1 / 2}-\Lambda^{-1 / 2}\right)$. Consistent with the original present value equation (9), a country's steady state NFL position can differ from zero depending on the long-run net export ratio $\Lambda=\exp (\lambda) \cdot{ }^{10}$ A country with a steady-state trade surplus $(\Lambda>1)$ will be an international debtor and one with a trade deficit $(\Lambda<1)$ will be an international creditor. Notice, also, that factors affect the steady state value for $N F L_{t} / \mathcal{T}_{t}$ via their impact on the expected $\mathrm{SDF}, \kappa$, that determines the size of $\rho$. In particular, factors that raise $\kappa$ increase the effect of any trade imbalance on the steady state value for $N F L_{t} / \mathcal{T}_{t}$.

The approximation also enables us to easily identify the trade and valuation channels of international adjustment. Adjustment through the trade channel occurs when agents revise their expectations concerning future trade flows. ${ }^{11}$ For example, upward revisions in expectations about the secular trend in net exports increase $N F L_{t} / \mathcal{T}_{t}$ via a rise in $\overline{n f l}_{t}$, as do revisions in expectations about the cyclical net export ratio via a rise $n f l_{t}$. In economic terms, a country can support a larger international debt position when there is an upward revision in agents' expectations about the size of future trade surpluses. Upward revisions in expectations about future trade growth, $\Delta \tau_{t}$, have a similar impact via $n f l_{t}$ when $\eta>0$ because higher expected growth implies larger future trade surpluses.

Adjustment through the valuation channel occurs when agents revise their expectations about

\footnotetext{
${ }^{10}$ The steady-state value for $N F L_{t} / \mathcal{T}_{t}$ implied by (9) also depends on the second- and higher-order moments of the joint distribution governing future trade flows and SDF, but these moments are ignored by the approximation.

${ }^{11}$ Note that trade flows have two effects on a country's external position: Imbalances between the flows of imports and exports during period $t$ directly affect end-of-period asset and liability holdings, while expectations concerning future trade flows (in periods $t+1$ and beyond) affect the value of asset and liability holdings at the end of period $t$. Current shocks to exports and imports only produce external adjustments via the trade channel if they change these expectations.
} 
the SDF. These revisions in expectations produce changes in $N F L_{t} / \mathcal{T}_{t}$ via the cyclical component. For intuition consider the effect of news that lowers expectations concerning the future SDF but has no effect on future trade flows. If the country is expected to run a steady state trade surplus (i.e., when $\eta>0$ ), the first-order effect is a fall in its NFL position as future surpluses are discounted more heavily. The approximation captures this valuation effect via the first term on the right of equation (12). Conversely, if the country is expected to run a steady state trade deficit (i.e., when $\eta<0$ ), the first-order valuation effect works in the opposite direction because future deficits are discounted more heavily. This theoretical ambiguity in the direction of the valuation channel is implied by the original present value expression. An inspection of (9) reveals that the effects of revisions in agents' expectations concerning the future SDF on a country's current NFL position also depend on their current expectations about future trade flows.

The approximation in (10)-(12) differs in several ways from other approximations based on the consolidated budget constraint in (1). G\&R use (1) to derive an approximated present value expression for the cyclical component of a country's external position; a measure which combines $\log$ deviations of foreign assets, liabilities, exports and imports from their respective trends. In contrast, the approximation above allows us to study the dynamics of the whole external position, i.e. changes in both the secular and cyclical components of $N F L_{t} / \mathcal{T}_{t}$. C\&K also derive an approximation from (1) that links a combination of cointegrating relations between the current levels of log foreign assets, liabilities, consumption and (net) output to the present value of future output growth, consumption growth, and returns. As the authors stress, their approach allows for the presence of both deterministic and stochastic trends in the variables, whereas G\&R analysis focuses on de-trended series. My approximation also allows for the presence of both deterministic and stochastic trends but it places fewer cointegrating restrictions on the variables than $\mathrm{C} \& \mathrm{~K}$. In particular, assumptions A1-A3 and (12) imply that $n f l_{t}$ is stationary, but it does not restrict $\log$ foreign assets and liabilities to share the same stochastic trend as log exports and imports. ${ }^{12}$

Perhaps the most significant feature of the approximation in (10)-(12) concerns the presence of the future SDFs rather than returns. In contrast, G\&R and $C \& K$ derive approximations involving returns from the consolidated budget constraint and a no-Ponzi condition. Section 1.1 showed that this approach requires the identification of expected future returns on net foreign liabilities $R_{t+i}^{\mathrm{NFL}}=\varrho_{t+i} R_{t+i}^{\mathrm{FL}}-\left(\varrho_{t+i}-1\right) R_{t+i}^{\mathrm{FA}}$, where $\varrho_{t}=F L_{t} / N F L_{t}$ is the liability share. To avoid modeling future liability shares, both $G \& R$ and $C \& K$ approximate these returns around

\footnotetext{
${ }^{12}$ Since $N F L_{t} / \mathcal{T}_{t}=\left(F L_{t} / \mathcal{T}_{t}\right)-\left(F A_{t} / \mathcal{T}_{t}\right), F L_{t} / \mathcal{T}_{t}$ and $F A_{t} / \mathcal{T}_{t}$ may contain unit roots so long as they are cointegrated one-for-one. Unit root tests (reported in the Appendix) fail to reject the presence of the unit root in both $F L_{t} / \mathcal{T}_{t}$ and $F A_{t} / \mathcal{T}_{t}$ at standard significance levels, but tests of the null that $N F L_{t} / \mathcal{T}_{t}$ contains a unit root are statistically significant.
} 
the point where $\varrho_{t}$ is constant, but this a poor approximation to actual returns on net liabilities in the data. ${ }^{13}$ In contrast, the approximation in (10)-(12) avoids the need to approximate returns on net foreign liabilities by using the no-arbitrage condition in (2). This still leaves the question of how to accurately identify the SDF, but as the next section shows, this is readily accomplished using data on returns and other variables.

\section{The Model}

The model based on (10)-(12) comprises a specification for: (i) the secular dynamics in $N F L_{t} / \mathcal{T}_{t}$ and $\ln \left(N X_{t}\right)$; (ii) the SDF; and (iii) agents' expectations that drive the cyclical dynamics in $N F L_{t} / \mathcal{T}_{t}$.

\subsection{Secular Dynamics}

Figure 1 showed a persistent rise in $N F L_{t} / \mathcal{T}_{t}$ and a fall in $\ln \left(N X_{t}\right)$ over the past 60 years. These features of the data are inconsistent with (10)-(12) if agents' expectations about the secular trend in $\ln \left(N X_{t}\right)$ are solely based on the sample behavior. A prolonged rise in $N F L_{t} / \mathcal{T}_{t}$ must come from an increase in $\overline{n f l}_{t}$ driven by expectations of a rising secular trend in net exports that contrasts with the downward trend in $\ln \left(N X_{t}\right)$ during the sample. In light of this, I do not identify $\overline{n f l}_{t}$ from equation (11) with estimates of agents' expectations. Instead I estimate $\overline{n f l}_{t}$ and $\overline{n x}_{t}$ directly as linear time trends. As a practical matter, modeling $\overline{n f l}_{t}$ as a linear rather than a nonlinear function of time makes no difference because the rise in $N F L_{t} / \mathcal{T}_{t}$ over the sample is very steady. In the case of the $\ln \left(N X_{t}\right)$ series, linear and nonlinear estimates (computed from the H-P filter) of the secular trend are somewhat different before 1960, but I use the linear estimates for simplicity. ${ }^{14}$

Estimating $\overline{n f l}_{t}$ and $\overline{n x}_{t}$ in this manner is consistent with equation (11) under assumption A3. Suppose that agents' expectations take the form: $\lambda_{t}(i)=\lambda+\sum_{j=1}^{J} \pi_{j} \phi_{j}^{i}\left(\lambda-\overline{n x}_{t}\right)$ for some coefficients $\pi_{j}$ and $\phi_{j}$ with $0<\phi_{j}<1$. Clearly, $\lim _{i \rightarrow \infty} \lambda_{t}(i)=\lambda$ as A3 requires. Moreover, combining these expectations with (11) gives $\overline{n f l}_{t}=\eta \rho+\Phi\left(\lambda-\overline{n x}_{t}\right)$ with $\Phi=\psi \sum_{j=1}^{J} \pi_{j} \frac{\rho \phi_{j}}{1-\rho \phi_{j}}$, so the estimates of $\overline{n x}_{t}$ can produce a linear path for $\overline{n f l}_{t}$. I use the model estimates to study the

\footnotetext{
${ }^{13}$ Actual liability shares vary considerably in the data, particular during the late 1980s when the U.S. turned from a net creditor to a net debtor. Liability shares are less variable towards the end of the sample, but even then the approximation used by G\&R and C\&K is inaccurate: A regression of $R_{t}^{\mathrm{NFL}}$ on $R_{t}^{\mathrm{FL}}$ and $R_{t}^{\mathrm{FA}}$ on a the last 20 years of my data produces an $R^{2}$ coefficient of just 0.55 . Re-estimating the regression over the whole data sample (which includes much more variability in the liability share) produces a much lower $R^{2}$. [Strictly speaking, G\&R and $\mathrm{C} \& \mathrm{~K}$ approximate the returns on net foreign assets (i.e., minus one times the net return on foreign liabilities), but I ignore this "change of sign" in my discussion for clarity.]

${ }^{14} \mathrm{G} \& \mathrm{R}$ and $\mathrm{C} \& \mathrm{~K}$ also use deterministic trends to capture the persistent movements in the data.
} 
expectations that implicitly link my estimates of $\overline{n f l}_{t}$ and $\overline{n x}_{t}$ in Section 6.1. Again, I should emphasize that the estimates of $\overline{n f l}_{t}$ and $\overline{n x}_{t}$ only serve to identify the secular trends in the sample. They should not be interpreted as trends that will continue indefinitely.

\subsection{The Stochastic Discount Factor}

I estimate the $\log \mathrm{SDF}, \kappa_{t}$, from data on U.S. asset and liability returns and a set of information variables that characterize the conditioning information found in the no-arbitrage conditions. First, I rewrite in the no-arbitrage conditions in terms of unconditional expectations and the information variables. I then posit a specification for $\kappa_{t}$ that satisfies these conditions, and show how it can be estimated from the data.

Consider the no-arbitrage condition $1=\mathbb{E}_{t}\left[\exp \left(\kappa_{t+1}+r_{t+1}^{n}\right)\right]$, where $r_{t+1}^{n}$ denotes the $\log$ return on asset/liability $n$. If an information variable $\omega_{t}^{j}$ is known to agents in period $t$, then, by the law of iterated expectations, $1=\mathbb{E}\left[\exp \left(\lambda_{t+1}+r_{t+1}^{n}\right) \mid \omega_{t}^{j}\right]$. Multiplying both sides of this expression by $\exp \left(\omega_{t}^{j}\right)$, taking unconditional expectations, and re-arranging produces,

$$
1=\mathbb{E}\left[\exp \left(\kappa_{t+1}+r_{t+1}^{n, j}\right)\right]
$$

where $r_{t+1}^{n, j}=r_{t+1}^{n}+\omega_{t}^{j}-\ln \mathbb{E}\left[\exp \left(\omega_{t}^{j}\right)\right]$. This equation contains unconditional expectations, rather than the conditional expectations found in the original no-arbitrage condition, and adjusted log

returns, $r_{t+1}^{n, j}$, rather than log returns, $r_{t+1}^{n}$. Moreover, it holds for any information variable $\omega_{t}^{j}$ known to agents in period $t$. So if the original no-arbitrage condition holds for $n=1,2, \ldots N$ assets/liabilities, and we have a set of $j=1,2, \ldots J$ information variables known to agents in period $t$, the $\log$ SDF satisfies the set of $K=J N$ equations in the form of (13).

Next, let $\mathbf{e r}_{t+1}$ denote a $K \times 1$ vector of log excess returns, with elements $e r_{t+1}^{k}=r_{t+1}^{k}-r_{t+1}^{\mathrm{TB}}$, where $r_{t+1}^{\mathrm{TB}}$ is the $\log$ return on U.S. T-bills and $r_{t+1}^{k}$ is the $k^{\prime} t h$. $\log$ adjusted return $r_{t+1}^{n, j}$. I assume that the log SDF is given by

$$
\kappa_{t+1}=\alpha-r_{t+1}^{\mathrm{TB}}-\beta^{\prime}\left(\mathbf{e r}_{t+1}-\mathbb{E}\left[\mathbf{e r}_{t+1}\right]\right)
$$

for some constant $\alpha$ and $K \times 1$ vector $\beta$. These parameters are pinned down by (13). In the case of the $k^{\prime}$ th. adjusted return $r_{t+1}^{k}$, and assuming that $\kappa_{t+1}$ and $r_{t+1}^{k}$ are jointly normally distributed,

$$
1=\mathbb{E}\left[\exp \left(\kappa_{t+1}+r_{t+1}^{k}\right)\right]=\exp \left(\mathbb{E}\left[\kappa_{t+1}+r_{t+1}^{k}\right]+\frac{1}{2} \mathbb{V}\left[\kappa_{t+1}+r_{t+1}^{k}\right]\right)
$$


Substituting for $\kappa_{t+1}$ from (14), taking logs and re-arranging, produces

$$
\alpha+\mathbb{E}\left[e r_{t+1}^{k}\right]+\frac{1}{2} \mathbb{V}\left[e r_{t+1}^{k}\right]+\frac{1}{2} \beta^{\prime} \mathbb{V}\left[\mathbf{e r}_{t+1}\right] \beta=\mathbb{C V}\left[e r_{t+1}^{k}, \mathbf{e r}_{t+1}^{\prime}\right] \beta
$$

where $\mathbb{V}[$.$] and \mathbb{C V}[.,$.$] denote the variance and covariance, respectively. This equation must hold$ for the T-bill return (i.e., when $r_{t+1}^{k}=r_{t+1}^{\mathrm{TB}}$, or $e r_{t+1}^{k}=0$ ) so

$$
\alpha+\frac{1}{2} \beta^{\prime} \mathbb{V}\left[\mathbf{e r}_{t+1}\right] \beta=0
$$

Furthermore, imposing this restriction on (16) gives $\mathbb{E}\left[e r_{t+1}^{k}\right]+\frac{1}{2} \mathbb{V}\left[e r_{t+1}^{k}\right]=\mathbb{C V}\left[e r_{t+1}^{k}, \mathbf{e r}_{t+1}^{\prime}\right] \beta$, an equation that holds for each of the $K$ adjusted returns. Stacking the $K$ equations we obtain

$$
\mathbb{E}\left[\mathbf{e r}_{t+1}\right]+\frac{1}{2} \operatorname{diag}[\Omega]=\Omega \beta,
$$

where $\Omega=\mathbb{V}\left[\mathbf{e r}_{t+1}\right]$ and $\operatorname{diag}[\Omega]$ is a $K \times 1$ vector containing the leading diagonal of $\Omega$. Equations (17) and (18) pin down $\alpha$ and $\beta$, so we can rewrite (14) as

$$
\kappa_{t+1}=-\frac{1}{2} \mu^{\prime} \Omega^{-1} \mu-r_{t+1}^{\mathrm{TB}}-\mu^{\prime} \Omega^{-1}\left(\mathbf{e r}_{t+1}-\mathbb{E}\left[\mathbf{e r}_{t+1}\right]\right),
$$

where $\mu=\mathbb{E}\left[\mathbf{e r}_{t+1}\right]+\frac{1}{2} \operatorname{diag}[\Omega]$. Equation (19) identifies the log SDF from the moments of adjusted returns that satisfy the no-arbitrage condition in (13).

I estimate $\kappa_{t}$ from (19) using estimated moments of adjusted returns from the sample. Notice that this estimation method does not assume that the specification for the SDF in (19) is unique. Indeed, many SDFs exist when markets are incomplete. Equation (19) simply identifies one specification for the SDF that satisfies the no-arbitrage conditions. Nor does the method attempt to relate the SDF to macro variables (other than their possible use as information variables). Such an undertaking would require a general equilibrium model. My more modest goal is to examine the role of the SDF as a proximate driver of U.S. external adjustment.

The no-arbitrage condition for return $n$ implies that $1=\mathbb{E}\left[\exp \left(\lambda_{t+1}+r_{t+1}^{n}\right) \mid \omega_{t}^{j}\right]$ holds for every variable $w_{t}^{j}$ known to agents at time $t$, so (13) holds for a very large number of equations. In practice, there is a limit to the number of information variables that can be incorporated into the SDF estimates. I choose information variables that have forecasting power for log excess returns. In addition, I examine the robustness of my estimates to the use of different returns and choices for information variables, and I test for misspecification due to any approximation error in (15). 


\subsection{Cyclical Dynamics}

The cyclical component in $N F L_{t} / \mathcal{T}_{t}$ is driven by agents' expectations concerning the future $\log$ $\mathrm{SDF}$, the growth in trade and the cyclical variations in the net export ratio, which I write in a vector $z_{t}=\left[\kappa_{t}-\kappa, \Delta \tau_{t}-g, n x_{t}\right]^{\prime}$. I represent the dynamics of $z_{t}$ in a state space model where agents' expectations follow a finite order (covariance stationary) VAR:

$$
\mathbb{E}_{t} z_{t+1}=\sum_{i=1}^{\mathbb{N}} a_{i} \mathbb{E}_{t-i} z_{t+1-i}+v_{t}
$$

where the $a_{i}$ 's are $3 \times 3$ matrices. The $3 \times 1$ vector of innovations, $v_{t}$, is driven by agents' forecast errors, $e_{t}=z_{t}-\mathbb{E}_{t-1} z_{t}$, and news shocks, $\xi_{t}$ :

$$
v_{t}=b e_{t}+\xi_{t},
$$

where $b$ is a $3 \times 3$ matrix and $\xi_{t}$ is a $3 \times 1$ vector of mean-zero serially uncorrelated random variables, independent from $e_{t}$. Agents revise their expectations about future $z_{t}^{\prime} s$ in response to forecast errors and news shocks. For example, the case of first-order VAR, (20) and (21) imply that $\mathbb{E}_{t} z_{t+h}-\mathbb{E}_{t-1} z_{t+h}=a_{1}^{h}\left(b e_{t}+\xi_{t}\right)$ for all $h>0$. The $b$ matrix determines the responsiveness of expectations to forecast errors. I refer to $\xi_{t}$ as news shocks because they revise agents' expectations without a contemporaneous effect on $z_{t}$. In the first-order VAR case, (20) and (21) imply that $z_{t+1}=a_{1} z_{t}+e_{t+1}+\left(b-a_{1}\right) e_{t}+\xi_{t}$. The lagged effect of news shocks on $z_{t}$ illustrated in this example applies when expectations follow a higher order VAR.

I use equations (11), (20) and (21) to derive the dynamics of $n f l_{t}$, and $z_{t}$. For ease of exposition, consider the first-order case (with $a_{1}=a$ ). Under these circumstances, (11) implies that

$$
n f l_{t}=\gamma \mathbb{E}_{t} z_{t+1} \quad \text { with } \quad \gamma=\rho\left[\eta\left(\ell_{\kappa}+\ell_{\tau}\right)+\psi \ell_{n x}\right](\mathrm{I}-\rho \mathrm{a})^{-1}
$$

where $\ell_{j}$ picks out variable $j$ from $z_{t}$ (e.g. $\ell_{n x} z_{t}=n x_{t}$ ). Equations $(20),(21)$ and $(22)$ can now be used to write the dynamics of $n f l_{t}$, and $z_{t}$ in state space form:

$$
\left[\begin{array}{c}
\mathbb{E}_{t} z_{t+1} \\
z_{t}
\end{array}\right]=\left[\begin{array}{cc}
a & 0 \\
I & 0
\end{array}\right]\left[\begin{array}{c}
\mathbb{E}_{t-1} z_{t} \\
z_{t-1}
\end{array}\right]+\left[\begin{array}{cc}
b & I \\
I & 0
\end{array}\right]\left[\begin{array}{c}
e_{t} \\
\xi_{t}
\end{array}\right]
$$

and

$$
\left[\begin{array}{c}
n f l_{t} \\
z_{t}
\end{array}\right]=\left[\begin{array}{cc}
\gamma & 0 \\
0 & I
\end{array}\right]\left[\begin{array}{c}
\mathbb{E}_{t} z_{t+1} \\
z_{t}
\end{array}\right]
$$


or, more compactly,

$$
Z_{t}=A Z_{t-1}+B U_{t} \quad \text { and } \quad Y_{t}=\Gamma Z_{t}
$$

where $Z_{t}=\left[\mathbb{E}_{t} z_{t+1}^{\prime}, z_{t}^{\prime}\right]^{\prime}$ is the (partially observed) state vector, and $Y_{t}=\left[n f l_{t}, z_{t}^{\prime}\right]^{\prime}$ is the vector of observed data. Higher order specifications for the agents' expectations can also be written in the form of (24) with suitable expansion of the state vector to include lagged values of $\mathbb{E}_{t} z_{t+1}$ and a modification of the $\gamma$ vector.

For estimation purposes, I assume that the forecast errors and news shocks are normally distributed mean-zero random variables with covariance matrices $\Sigma_{e}$ and $\Sigma_{\xi}$, respectively. The parameters to be estimated include the elements of these matrices (including off-diagonal terms), the VAR matrices $a$ and $b$, and the value for $\Lambda$ that determines the coefficients $\eta=\frac{1}{1-\rho}\left(\Lambda^{1 / 2}-\right.$ $\left.\Lambda^{-1 / 2}\right)$ and $\psi=\frac{1}{2}\left(\Lambda^{1 / 2}+\Lambda^{-1 / 2}\right)$. I estimate these parameters by maximum likelihood with the aid of the Kalman Filter using a calibrated value for $\rho$ described below.

This state space model for the cyclical dynamics has a number of noteworthy features. First, it treats agents' expectations, $\mathbb{E}_{t} z_{t+1}$, as dynamic factors that drive $n f l_{t}$ via the present value restrictions in (11), and realizations of $z_{t+1}$. Second, the model imposes the restrictions implied by (11) in the determination of the $\gamma$ vector that links $n f l_{t}$ and $\mathbb{E}_{t} z_{t+1}$ in equation (22). This produces a more parsimonious specification than if the coefficients in $\gamma$ were left unrestricted. Third, the model satisfies the orthogonality restrictions implied by rational expectations because the forecast errors $e_{t}$ are part of the error vector $U_{t}$ in the state equation that is orthogonal to $Z_{t-1}$.

Following Campbell and Shiller (1987) (C\&S), a standard approach for evaluating present value expressions like those in (11) is to consider the cross-equation restrictions they imply on a finite-order VAR. To understand how this approach differs from my analysis, consider the implications of the state space model for the joint dynamics of $n f l_{t}$ and $z_{t}$ when agents' expectations in (20) follow a first-order process:

$$
\begin{aligned}
{\left[\begin{array}{c}
n f l_{t} \\
z_{t}
\end{array}\right]=} & {\left[\begin{array}{cc}
\gamma a \Theta & \gamma a(I-\Theta \gamma) a \\
\Theta & (I-\Theta \gamma) a
\end{array}\right]\left[\begin{array}{c}
n f l_{t-1} \\
z_{t-1}
\end{array}\right]+\left[\begin{array}{cc}
\gamma b & \gamma \\
I & 0
\end{array}\right]\left[\begin{array}{l}
e_{t} \\
\xi_{t}
\end{array}\right] } \\
& +\left[\begin{array}{cc}
\gamma a(I-\Theta \gamma)(b-a) & \gamma a(I-\Theta \gamma) \\
(I-\Theta \gamma)(b-a) & (I-\Theta \gamma)
\end{array}\right]\left[\begin{array}{c}
e_{t-1} \\
\xi_{t-1}
\end{array}\right],
\end{aligned}
$$

where $\Theta$ is a $3 \times 1$ vector of coefficients from the projection of $z_{t}-a z_{t-1}$ on $n f l_{t}-\gamma a z_{t}$. In general, $\Theta \gamma \neq I$, so the joint dynamics of $n f l_{t}$ and $z_{t}$ are given by a $\operatorname{VARMA}(1,1)$ process which need not have a finite-order VAR representation. Thus, it is possible that tests of the cross-equations 
restrictions applied to estimates of a finite order VAR would incorrectly reject the present value relation in equation (11).

Equation (25) also illustrates the role played by agents' information. Suppose that $b=a$ so $z_{t}=a z_{t-1}+e_{t}+\xi_{t-1} \cdot{ }^{15}$ Here agents' expectations differ from time series forecasts conditioned on current and past $z_{t}$ 's. Consequently, the value for $n f l_{t}$ implied by the present value relation (i.e., $n f l_{t}=\gamma a z_{t}+\gamma \xi_{t}$ ) differs from the value implied by (11) using the times series forecasts (i.e., $n f l_{t}=\gamma a z_{t}$ ). A key insight from C\&S is that time series forecasts can be used to assess the present value relation in (11) if they utilize current and past values of both $z_{t}$ and $n f l_{t}$. To this end, consider the time series forecast: $\mathbb{E}\left[z_{t+1} \mid z_{t}, n f l_{t}, \ldots\right]=a z_{t}+\Theta\left(n f l_{t}-\gamma a z_{t}\right)$, where $\Theta=\Sigma_{\xi} \gamma^{\prime} /\left(\gamma \Sigma_{\xi} \gamma^{\prime}\right) .{ }^{16}$ Since $n f l_{t}-\gamma a z_{t}=\gamma \xi_{t}$, the forecast replicates agents' expectations when $\Theta \gamma=I$. This condition holds when agents only receive news about one of the variables in $z_{t}$. In this case, data on $n f l_{t}$ and $z_{t}$ are jointly sufficient to reveal agents' information. Moreover, (25) now simplifies to a first-order VAR, so the cross-equation restrictions implied by the present value relation can be assessed with the C\&S method. Alternatively, if agents receive news about multiple variables in $z_{t}$, observations on $n f l_{t}$ and $z_{t}$ are not jointly sufficient to reveal the conditioning information agents' use in forming expectations. In this case, $\Theta \gamma \neq I$, so (25) (with $b=a$ ) retains the moving average structure and there is no guarantee that the joint process for $n f l_{t}$ and $z_{t}$ has the finite-order VAR representation assumed by the C\&S method.

In sum, there are three key differences between the state space model I use to estimate the cyclical dynamics and the standard C\&S approach. First, it imposes the "cross-equation" restrictions implied by the present value relation in (11). Second, it allows us to easily estimate the effects of news concerning the future SDF and trade flows. These effects turn out to be empirically important. Third, the model accommodates the moving average structure that arises when agents' expectations differ from time series forecasts.

\section{Empirical Analysis}

\subsection{Data}

My empirical analysis uses quarterly data on U.S. foreign asset and liability positions, returns, trade flows and other macro variables between 1952:I and 2013:IV. The data on positions and returns extends and updates the series constructed by G\&R (see Gourinchas and Rey 2005 for

\footnotetext{
${ }^{15}$ Note that $e_{t}$ and $\xi_{t-1}$ are mutually independent, serially uncorrelated vectors of random variables which are also uncorrelated with $z_{t-i}$ for $i>0$.

${ }^{16}$ The $\Theta$ vector is computed from the projection of $z_{t}-a z_{t-1}$ on $n f l_{t}-\gamma a z_{t}$ in the special case where $b=a$. The first term on the right-hand-side is the forecast conditioned on $z_{t}$, while the second identifies the incremental forecasting information contained in $n f l_{t}$.
} 
details). They computed the market values for four categories of U.S. foreign asset and liabilities: equity, foreign direct investment (FDI), debt and other, by combining data on international positions with information on the capital gains and losses. In effect, their procedure produces quarterly data on asset and liability positions that map into the International Investment Position (IIP) data reported by the Bureau of Economic Analysis (BEA) at the end of each year, with intra-year position changes computed from the capital gains on the individual securities that comprise the foreign asset or liability category. ${ }^{17}$ I estimate the SDF from the returns on the asset and liability categories. These returns are portfolio weighted averages of the returns on the individual securities that comprise each category computed from market prices. All positions and returns are computed in constant U.S. dollars. ${ }^{18}$ I also use data on the following macro variables: U.S. exports and imports (in constant dollars from the BEA); the return on 3-month U.S. T-bills; U.S. GDP (in constant dollars); (iv) the spread between the yields on 10-year U.S. government bonds and 3-month U.S.T-bills; and the trade-weighted real dollar exchange rate (from the Federal Reserve Board).

Figure 2: Cyclical Components

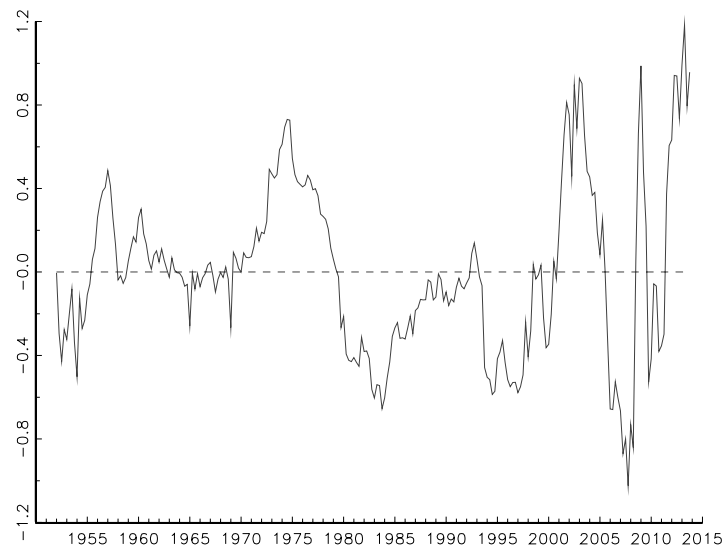

$\mathrm{A}: n f l_{t}$

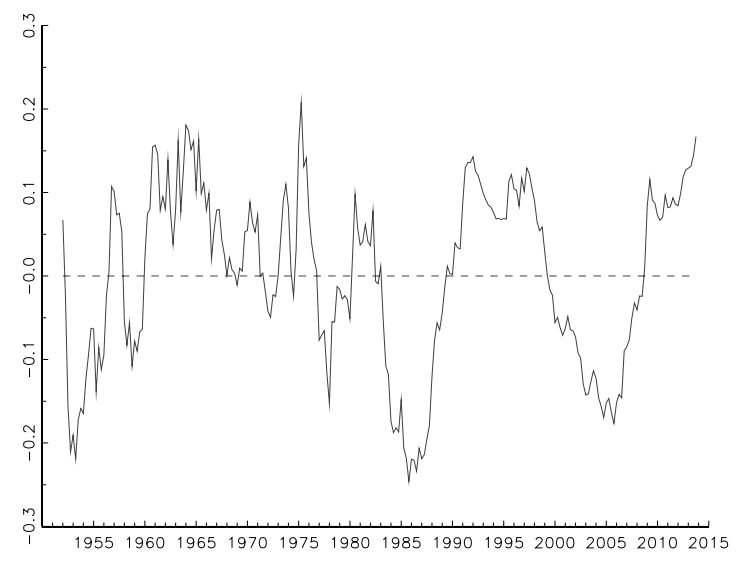

B: $n x_{t}$

Figure 2 shows that the cyclical components in $N F L_{t} / \mathcal{T}_{t}$ and $\ln \left(N X_{t}\right)$ display considerable variation over the sample. The cyclical movements in $N F L_{t} / \mathcal{T}_{t}$ after 2000 are particularly

\footnotetext{
${ }^{17} \mathrm{C} \& \mathrm{~K}$ also use quarterly data on asset and liability positions consistent with the IIP end-or-year positions, but they construct their intra-year positions by interpolation without regard to the quarter-by-quarter gains and losses on the underlying securities. As Gourinchas, Rey, and Truempler (2012) show, these gains and losses are significant during the 2008-9 financial crisis. I also note that IIP position data has some limitations. As Zucman (2013) points out, it doesn't accurately reflect assets held in offshore accounts. I discuss the possible influence of offshore holdings on my findings in Section 6.

${ }^{18} \mathrm{It}$ is worth emphasizing that this method for computing returns differs from the one used by early papers in the literature (e.g., Lane and Milesi-Ferretti, 2005; Gourinchas and Rey, 2007b and Meissner and Taylor, 2006) based on the IIP data. Curcuru, Dvorak, and Warnock (2007) and Lane and Milesi-Ferretti (2009) argue that inaccuracies in these data lead to upwardly biased estimates of average returns. See Gourinchas and Rey (2013) for detailed comparisons.
} 
Table 1: Summary Statistics

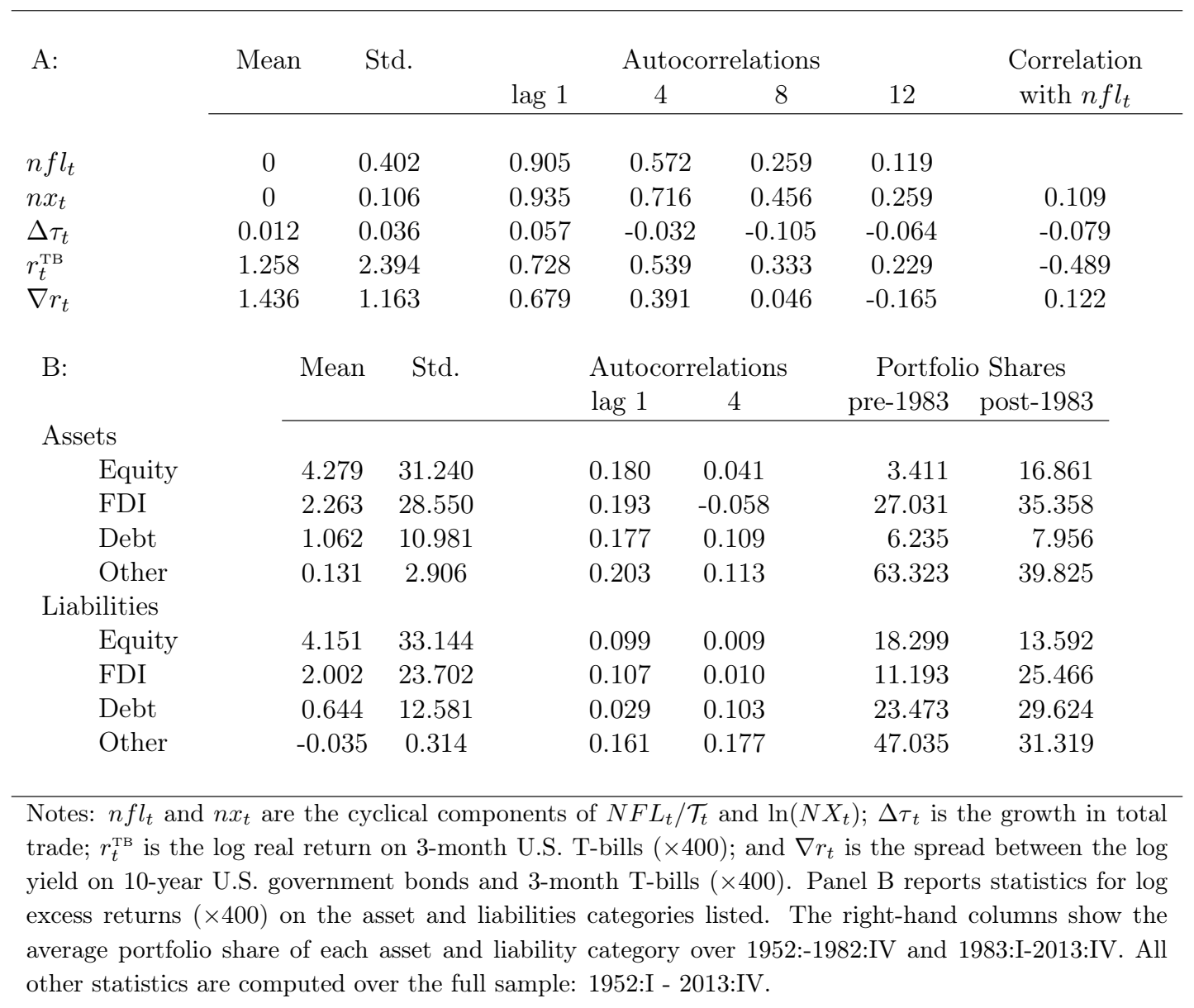

noteworthy because they primarily reflect the sizable capital gains and losses on U.S. asset and liability positions produced by changes in securities prices and exchange rates. The empirical model will allow us to quantify the contributions of the trade and valuation channels to these variations.

Table 1 reports summary statistics for the key variables. Consistent with the visual evidence in Figure 2, Panel A shows that the $n f l_{t}$ and $n x_{t}$ series display strong serial correlation, but the autocorrelations die out quickly at longer lags. T-bill returns and the yield spread also display significant serial correlation. In contrast, there is little serial correlation in trade growth. All of these time series appear covariance stationary. The right-hand-column shows a small positive correlation between $n f l_{t}$ and $n x_{t}$, and a comparatively large negative correlation between $n f l_{t}$ and $r_{t}^{\mathrm{TB}}$. These correlations provide preliminary evidence pointing to the importance of the valuation channel because $r_{t}^{\mathrm{TB}}$ covaries negatively with the log SDF.

Panel B of Table 1 presents statistics for log excess returns on the four asset and liability 
categories. Here we see that there are small differences between the returns on assets and liabilities within a category, and comparatively large differences across categories. For example, the average excess return on equity assets and liabilities is 4.28 and 4.15 percent, respectively; more than twice the average excess return on debt assets or liabilities. ${ }^{19}$ This pattern is reflected in the volatility of returns, measured by their sample standard deviations. There has been considerable change in the composition of asset and liability holdings over the sample period. As an indicator of these changes, Panel B also shows how the average shares in of each category in total asset and total liabilities differ between the first and second half of the sample.

Recent papers by Lane and Milesi-Ferretti (2005), Meissner and Taylor (2006), Curcuru, Dvorak, and Warnock (2007), Forbes (2009) and others examine the composition of and returns on U.S. foreign asset and liability holdings. Much of this research focuses on the question of whether the U.S. enjoyed an "Exorbitant Privilege" by earning systematically higher returns on its assets than its liabilities. In my data, average asset returns exceed average liability returns before 2008, but there is no significant difference in average returns computed over the entire sample period because asset returns are much lower than liability returns at the height of the 2008-9 crisis. These findings are consistent with the studies cited above using pre-crisis data (see Gourinchas and Rey, 2013). They also support the view advanced by Gourinchas, Rey, and Govillot (2010) and Gourinchas, Rey, and Truempler (2012) that the U.S. acts as a global insurer, receiving implicit premiums via the "Exorbitant Privilege" and making implicit payments during a crisis via disproportionate losses on foreign assets relative to liabilities. In contrast to these papers, my analysis does not focus directly on average asset and liability returns. Instead, I use the set of excess returns to estimate the SDF used in the present value restriction that determines the external position. The question of whether the behavior of the SDF provides some measurable benefit to the U.S. with respect to its external position is addressed in Section 6.

\section{Estimation Results}

\subsection{Stochastic Discount Factor}

I consider two specifications for the $\log \mathrm{SDF}$. The first, denoted by $\hat{\kappa}_{t}^{\mathrm{I}}$, is estimated from (19) without information variables using seven $\log$ excess returns and the return on U.S. T-bills. ${ }^{20}$

\footnotetext{
${ }^{19}$ It is worth emphasizing that these statistics are computed from the entire sample period. When average returns computed over shorter spans there are larger differences between the excess returns on assets and liabilities within a category, consistent with the findings in Habib (2010).

${ }^{20}$ Excess returns on FDI and equity liabilities are very closely correlated, so I only the equity returns.
} 
To test whether $\hat{\kappa}_{t}^{\mathrm{I}}$ satisfies the no-arbitrage condition $1=\mathbb{E}\left[\exp \left(\hat{\kappa}_{t+1}^{\mathrm{I}}+r_{t+1}^{i}\right) \mid \omega_{t}^{j}\right]$, I estimated regressions of the form:

$$
\exp \left(\hat{\kappa}_{t+1}^{\mathrm{I}}+r_{t+1}^{i}\right)-1=d_{0}+d_{1} \omega_{t}^{1}+d_{2} \omega_{t}^{2}+\ldots .+d_{J} \omega_{t}^{J}+v_{t+1}
$$

for the $\log$ return, $r_{t}^{i}$, and test the statistical significance of the coefficients on the information variables $\omega_{t}^{j}$. Panel A of Table 2 reports the results using the share of assets held in FDI, the share of liabilities held in equity, and the spread as information variables. The share variables embed agents' information insofar as they choose their international asset and liability positions with regard to expected future returns. Similarly, the spread reflects, in part, agents' expectations concerning future interest rates. As the table shows, the estimated coefficients are individually and jointly statistically significant in each regression. Clearly, then, the $\hat{\kappa}_{t}^{\mathrm{I}}$ specification doesn't adequately account for the role of conditioning information in the no-arbitrage conditions.

Table 2: SDF Specification Tests

\begin{tabular}{|c|c|c|c|c|c|c|c|c|c|c|c|}
\hline \multirow[b]{2}{*}{ Return } & \multicolumn{5}{|c|}{ A: $\hat{\kappa}_{t}^{\mathrm{I}}$} & \multicolumn{6}{|c|}{ B: $\hat{\kappa}_{t}^{\mathrm{II}}$} \\
\hline & Share 1 & Share 2 & $\nabla r_{t}$ & $R^{2}$ & $\chi^{2}$ & Share 1 & Share 2 & $\nabla r_{t}$ & $n f l_{t}$ & $R^{2}$ & $\chi^{2}$ \\
\hline Equity Asset & $\begin{array}{l}0.344^{* *} \\
(0.070)\end{array}$ & $\begin{array}{c}0.287^{* *} \\
(0.081)\end{array}$ & $\begin{array}{c}-0.619^{* *} \\
(0.133)\end{array}$ & 0.096 & $\begin{array}{l}24.996 \\
(0.000)\end{array}$ & $\begin{array}{l}-0.116 \\
(0.085)\end{array}$ & $\begin{array}{l}-0.111 \\
(0.099)\end{array}$ & $\begin{array}{c}0.153 \\
(0.160)\end{array}$ & $\begin{array}{c}0.073 \\
(0.051)\end{array}$ & 0.015 & $\begin{array}{c}3.480 \\
(0.481)\end{array}$ \\
\hline FDI Asset & $\begin{array}{l}0.368^{* *} \\
(0.078)\end{array}$ & $\begin{array}{l}0.308^{* *} \\
(0.089)\end{array}$ & $\begin{array}{c}-0.664^{* *} \\
(0.147)\end{array}$ & 0.091 & $\begin{array}{l}23.477 \\
(0.000)\end{array}$ & $\begin{array}{l}-0.089 \\
(0.092)\end{array}$ & $\begin{array}{c}-0.092 \\
(0.107)\end{array}$ & $\begin{array}{c}0.104 \\
(0.173)\end{array}$ & $\begin{array}{c}0.079 \\
(0.056)\end{array}$ & 0.011 & $\begin{array}{c}2.644 \\
(0.619)\end{array}$ \\
\hline Debt Asset & $\begin{array}{l}0.420^{* *} \\
(0.089)\end{array}$ & $\begin{array}{l}0.351^{* *} \\
(0.102)\end{array}$ & $\begin{array}{c}-0.753^{* *} \\
(0.168)\end{array}$ & 0.090 & $\begin{array}{l}23.333 \\
(0.000)\end{array}$ & $\begin{array}{l}-0.036 \\
(0.105)\end{array}$ & $\begin{array}{c}-0.062 \\
(0.122)\end{array}$ & $\begin{array}{c}-0.008 \\
(0.197)\end{array}$ & $\begin{array}{c}0.111 \\
(0.063)\end{array}$ & 0.013 & $\begin{array}{c}3.139 \\
(0.535)\end{array}$ \\
\hline Other Asset & $\begin{array}{l}0.429^{* *} \\
(0.091)\end{array}$ & $\begin{array}{l}0.363^{* *} \\
(0.104)\end{array}$ & $\begin{array}{c}-0.775^{* *} \\
(0.171)\end{array}$ & 0.091 & $\begin{array}{l}23.603 \\
(0.000)\end{array}$ & $\begin{array}{l}-0.026 \\
(0.107)\end{array}$ & $\begin{array}{l}-0.048 \\
(0.124)\end{array}$ & $\begin{array}{c}-0.027 \\
(0.201)\end{array}$ & $\begin{array}{c}0.106 \\
(0.065)\end{array}$ & 0.011 & $\begin{array}{c}2.761 \\
(0.599)\end{array}$ \\
\hline Equity Liability & $\begin{array}{l}0.331^{* *} \\
(0.071)\end{array}$ & $\begin{array}{l}0.267^{* *} \\
(0.081)\end{array}$ & $\begin{array}{c}-0.586^{* *} \\
(0.134)\end{array}$ & 0.087 & $\begin{array}{l}22.370 \\
(0.000)\end{array}$ & $\begin{array}{l}-0.130 \\
(0.084)\end{array}$ & $\begin{array}{c}-0.132 \\
(0.098)\end{array}$ & $\begin{array}{c}0.193 \\
(0.158)\end{array}$ & $\begin{array}{c}0.068 \\
(0.051)\end{array}$ & 0.016 & $\begin{array}{c}3.792 \\
(0.435)\end{array}$ \\
\hline Debt Liability & $\begin{array}{l}0.425^{* *} \\
(0.091)\end{array}$ & $\begin{array}{l}0.356^{* *} \\
(0.104)\end{array}$ & $\begin{array}{c}-0.764^{* *} \\
(0.171)\end{array}$ & 0.089 & $\begin{array}{l}23.123 \\
(0.000)\end{array}$ & $\begin{array}{l}-0.031 \\
(0.106)\end{array}$ & $\begin{array}{l}-0.057 \\
(0.123)\end{array}$ & $\begin{array}{c}-0.020 \\
(0.199)\end{array}$ & $\begin{array}{c}0.114 \\
(0.064)\end{array}$ & 0.013 & $\begin{array}{c}3.235 \\
(0.519)\end{array}$ \\
\hline Other Liability & $\begin{array}{l}0.431^{* *} \\
(0.091)\end{array}$ & $\begin{array}{l}0.363^{* *} \\
(0.104)\end{array}$ & $\begin{array}{c}-0.777^{* *} \\
(0.172)\end{array}$ & 0.091 & $\begin{array}{l}23.492 \\
(0.000)\end{array}$ & $\begin{array}{c}-0.024 \\
(0.107)\end{array}$ & $\begin{array}{c}-0.049 \\
(0.125)\end{array}$ & $\begin{array}{l}-0.029 \\
(0.202)\end{array}$ & $\begin{array}{c}0.108 \\
(0.065)\end{array}$ & 0.012 & $\begin{array}{c}2.832 \\
(0.586)\end{array}$ \\
\hline T-bill & $\begin{array}{l}0.430^{* *} \\
(0.091)\end{array}$ & $\begin{array}{l}0.363^{* *} \\
(0.104)\end{array}$ & $\begin{array}{c}-0.776^{* *} \\
(0.172)\end{array}$ & 0.091 & $\begin{array}{l}23.499 \\
(0.000)\end{array}$ & $\begin{array}{l}-0.025 \\
(0.107)\end{array}$ & $\begin{array}{c}-0.049 \\
(0.125)\end{array}$ & $\begin{array}{l}-0.028 \\
(0.201)\end{array}$ & $\begin{array}{c}0.108 \\
(0.065)\end{array}$ & 0.012 & $\begin{array}{c}2.822 \\
(0.588)\end{array}$ \\
\hline
\end{tabular}

Notes: The table reports the OLS estimates of the regression (26) using the SDF I specification in panel A and SDF II specification in panel B. The information variables are: (i) the share of U.S. assets held in FDI (share 1), (ii) the share of U.S. liabilities held in equity (share 2), $\nabla r_{t}$ and $n f l_{t}$. White (1980) standard errors are reported in parenthesis below the coefficient estimates. "*** indicates statistical significance at the $5 \%$ level. $\chi^{2}$ statistics from a Wald test for the null that all the coefficients are zero (with p-value in parenthesis) are shown in the right-hand column. All regression estimated in quarterly data between 1952:I and 2013:IV.

The second specification for the $\log$ SDF, denoted by $\hat{\kappa}_{t}^{\mathrm{II}}$, uses the same returns and the information variables from regression (26). There is now a total of 21 adjusted excess returns, 
seven excess returns, and the T-bill return to incorporate into the SDF specification in (19). In principle, it should be possible to compute the log SDF directly using all these returns, but in practice, the high correlations between many of the adjusted excess returns produce an illconditioned covariance matrix. To mitigate this problem I computed $\hat{\kappa}_{t}^{\mathrm{II}}$ from (19) using the first two principle components of the 21 adjusted excess returns, the seven excess returns, and the T-bill returns. ${ }^{21}$ Then, I re-estimated regression (26) using $\hat{\kappa}_{t+1}^{\mathrm{II}}$ rather than $\hat{\kappa}_{t+1}^{\mathrm{I}}$ with $n f l_{t}$ as an additional information variable. As Panel B of Table 2 shows, none of the coefficient estimates is individually or jointly statistically significant in these regressions. Furthermore, these findings appear robust. Re-estimating the regressions with different information variables (including the macro variables from Table 1) produces similar results. ${ }^{22}$ I therefore use the $\hat{\kappa}_{t}^{\mathrm{II}}$ specification for the $\log$ SDF in my analysis below.

The $\hat{\kappa}_{t}^{\mathrm{II}}$ specification has several noteworthy features. First, it does not use the cyclical component in $N F L_{t} / \mathcal{T}_{t}$ as an information variable so there is no mechanical link between the dynamics of $\hat{\kappa}_{t}^{\text {II }}$ and the cyclical variations in $N F L_{t} / \mathcal{T}_{t}$. Second, the ex post errors $\exp \left(\hat{\kappa}_{t+1}^{\text {II }}+\right.$ $\left.r_{t+1}^{i}\right)-1$ are uncorrelated with the cyclical component of $N F L_{t} / \mathcal{T}_{t}$. This means that the valuation adjustments identified by the model estimates do not produce arbitrage opportunities. The results in Panel B also indicate that the approximation used to derive the equation for the log $\mathrm{SDF}$ in (19) is not a significant source of misspecification.

Table 3: Log SDF Statistics

\begin{tabular}{lcccccc}
\hline Specification & Mean & Std & \multicolumn{2}{c}{ Autocorrelations } \\
& & & $\operatorname{lag} 1 \quad \operatorname{lag} 4$ & Correlation & $\begin{array}{c}\text { Steady State } \\
\text { Risk Free Rate }\end{array}$ \\
\hline$\hat{\kappa}_{t}^{\mathrm{I}}$ & -0.046 & 0.293 & 0.219 & 0.158 & & 1.120 \\
$\hat{\kappa}_{t}^{\mathrm{II}}$ & -0.055 & 0.322 & 0.196 & 0.142 & 0.910 & 1.152 \\
\hline
\end{tabular}

Table 3 reports summary statistics for the two SDF specifications. The addition of conditioning information makes $\hat{\kappa}_{t}^{\mathrm{II}}$ slightly more volatile than $\hat{\kappa}_{t}^{\mathrm{I}}$ and lowers its average value.

\footnotetext{
${ }^{21}$ The first two principle components account for approximately 90 percent of the covariation in the adjusted excess returns. Adding the third and fourth components had no material effect on the estimated log SDF, so I worked with the more parsimonious specification.

${ }^{22}$ I also considered the robustness of my SDF estimates to the choice of excess returns. In particular, I examined whether omitting the returns on both FDI assets and liabilities significantly affected the estimates because these returns are arguably subject to most measurement error. Omitting these returns had little effect. The log SDF was highly correlated with $\hat{\kappa}_{t}^{\text {II }}$ and produced regression results like those in Panel B of Table 2.
} 
These differences have a small effect on the implied steady-state risk-free rate (computed as $\left.r=-\ln \left[\mathbb{E} \exp \left(\kappa_{t}\right)\right] \simeq-\mathbb{E}\left[\kappa_{t}\right]-\frac{1}{2} \mathbb{V}\left[\kappa_{t}\right]\right)$ shown in the right-hand column. By comparison, the average real return on U.S. T-bills is 1.258 percent, ten basis points higher than the rate implied by $\hat{\kappa_{t}^{\mathrm{II}}}$. Recall that the discount factor used in the present value equations is $\rho=\exp (g+\kappa)$ where $g=\mathbb{E} \Delta \tau_{t}$ and $\kappa=\mathbb{E} \kappa_{t}$. I use the sample averages for $\Delta \tau_{t}$ and $\hat{\kappa}_{t}^{\text {II }}$ to give an estimate of $\rho$ equal to 0.958 , consistent with Assumption A2. Finally, notice that both $\hat{\kappa}_{t}^{\mathrm{I}}$ and $\hat{\kappa}_{t}^{\mathrm{II}}$ exhibit only small amounts of serial correlation; the variations in both specifications display little persistence and there is no evidence of secular trends. This feature of the estimated log SDF is consistent with assumption A1. It implies that revisions in agents' expectations concerning the future SDF drive the cyclical not secular variations in $N F L_{t} / \mathcal{T}_{t}{ }^{23}$

\subsection{Cyclical Dynamics}

Table 4 shows results from estimating the state space model for the cyclical dynamics when agents' expectations follow a first-order VAR. ${ }^{24}$ The parameter estimates in Panel A display several noteworthy features. First, the estimate of 1.044 for $\Lambda$ implies a steady-state trade surplus equal to 4.3 percent of total trade. This is above the average value for $N X_{t}$ but is pinned down by the joint dynamics of $n f l_{t}$ and $\kappa_{t}$. Specifically, the present value restriction in (12) implies that $n f l_{t}$ covaries positively with $\mathbb{E}_{t} \kappa_{t+i}$ when $\eta=\frac{1}{1-\rho}\left(\Lambda^{1 / 2}-\Lambda^{-1 / 2}\right)>0$, so the estimate of $\Lambda$ needs to be greater than one for the model to account for the positive correlations between $n f l_{t}$ and future values of $\kappa_{t}$ in the data. ${ }^{25}$ In economic terms, agents must believe in a steady-state trade surplus to account for the rise and fall in $n f l_{t}$ when they revised their expectations for the future SDF upwards and downwards, respectively. Second, there are sizable differences between the estimated $a$ and $b$ matrices governing the dynamics of $\mathbb{E}_{t} z_{t+1}$. (A Wald test for the null that $a=b$ is highly statistically significant.) These estimates imply that the joint process for $n f l_{t}$ and $z_{t}$ contains a nontrivial moving average component. Panel A also shows the estimated variance-covariance matrices for the forecast errors, $\hat{\Sigma}_{e}$, and news shocks, $\hat{\Sigma}_{\xi}$. According to these estimates, there is little correlation between the forecast errors but news concerning the future SDF appears negatively correlated with news about net exports. As we shall see, this negative correlation produces offsetting roles for the trade and valuation channels.

\footnotetext{
${ }^{23}$ Both Bernanke (2005) and Gourinchas and Rey (2013) note that growth in external imbalances across the globe during the past 20 years has been accompanied by a long-term decline in average real interest rates across the G-7. This observation is consistent with the dynamics of $\hat{\kappa_{t}^{\mathrm{II}}}$ insofar as the decline in foreign interest rates reflects the effect of variations in dollar real exchange rates rather than a persistent rise in the SDF.

${ }^{24}$ I also estimated specifications with higher-order VARs, but they did not appear to better characterize the data.

${ }^{25}$ Variations in trade growth $\Delta \tau$ are much smaller than those of the log SDF, so covariation between $n f l_{t}$ and future $\Delta \tau_{t}$ 's play a smaller role in pinning down the estimate of $\Lambda$.
} 
Table 4: Model Estimates

$$
\begin{aligned}
& \text { A: } \quad \rho=0.958, \quad \hat{\Lambda}=1.044 \quad(0.011), \\
& \hat{a}=\left[\begin{array}{ccc}
1.076 & -2.035 & 0.061 \\
(0.126) & (0.541) & (0.113) \\
0.055 & 0.334 & 0.033 \\
(0.034) & (0.160) & (0.030) \\
0.009 & -0.465 & 0.911 \\
(0.070) & (0.439) & (0.056)
\end{array}\right] \quad \hat{b}=\left[\begin{array}{ccc}
0.002 & 0.261 & -1.677 \\
(0.019) & (0.164) & (1.451) \\
0.001 & 0.045 & -0.361 \\
(0.006) & (0.053) & (0.518) \\
0.001 & -0.108 & 1.284 \\
(0.008) & (0.084) & (0.590)
\end{array}\right] \\
& \hat{\Sigma}_{e}=\left[\begin{array}{ccc}
1047.902 & 5.094 & 1.260 \\
(98.359) & (7.459) & (8.493) \\
5.094 & 11.349 & -0.027 \\
(7.459) & (1.172) & (1.264) \\
1.260 & -0.027 & 4.140 \\
(8.493) & (1.264) & (5.959)
\end{array}\right] \quad \hat{\Sigma}_{\xi}=\left[\begin{array}{ccc}
0.670 & 0.082 & -1.872 \\
(2.590) & (1.276) & (3.128) \\
0.082 & 0.657 & 0.834 \\
(1.276) & (0.465) & (1.871) \\
-1.872 & 0.834 & 6.972 \\
(3.128) & (1.871) & (5.037)
\end{array}\right] \\
& \text { B: Innovation Autocorrelations LM-statistics }
\end{aligned}
$$

$\begin{array}{cccrccc} & \operatorname{lag} 1 & 2 & 3 & 4 & & \\ \kappa_{t} & 0.207 & -0.013 & 0.109 & 0.164 & 4.881 & (0.300) \\ n x_{t} & 0.011 & 0.102 & -0.041 & 0.013 & 1.991 & (0.737) \\ \Delta \tau_{t} & -0.007 & 0.051 & 0.085 & 0.093 & 0.833 & (0.934) \\ n f l_{t} & -0.025 & 0.069 & -0.071 & 0.034 & 1.585 & (0.811)\end{array}$

Notes: Panel A reports maximum likelihood estimates with asymptotic standard errors in parenthesis. Estimates of $\Sigma_{e}$ and $\Sigma_{\xi}$ are multiplied by 10000. Panel B reports the autocorrelations of the Kalman filter innovations for each variable, and LM statistics for forth-order serial correlation with asymptotic p-values in parenthesis computed from the $\chi_{4}^{2}$ distribution.

Panel B shows the autocorrelations in the estimated Kalman filter innovations. As is consistent with a correctly specified model, there is little evidence of serial correlation in the innovations associated with any of the data series. The table also reports LM statistics for forth-order serial correlation that appear to be statistically insignificant. As a further specification test, I also examined the cross-equation restriction implied by the presence value relation, as shown in equation (22): $n f l_{t}=\gamma \mathbb{E}_{t} z_{t+1}$. The three elements in $\gamma$ involve the parameters governing the process for agents' expectations and $\Lambda$, so the model imposes two restrictions. An LM test of these restrictions gives a p-value of 0.98 . 


\section{Adjustment Channels}

I now use the model estimates to examine how shocks contributed to the deterioration of the U.S. external position between 1954 and 2013 via the valuation and trade channels.

\subsection{Variance Contributions}

We can use the model estimates to decompose the cyclical variations in $N F L_{t} / \mathcal{T}_{t}$ into three components:

$$
n f l_{t}=\widehat{n f l}_{t}^{\kappa}+\widehat{n f l} l_{t}^{\Delta \tau}+\widehat{n f l}_{t}^{n x}
$$

where $\widehat{n f l}_{t}^{j}$ represents the estimates of the three terms of the right-hand-side of (12). I compute these terms from the estimates in Table 4 as

$$
\begin{array}{rlrl}
\widehat{n f l}_{t}^{\kappa} & =\hat{\gamma}_{\kappa} \hat{\mathbb{E}}_{t} z_{t+1}, & & \hat{\gamma}_{\kappa}=\frac{\rho}{1-\rho}\left(\hat{\Lambda}^{1 / 2}-\hat{\Lambda}^{-1 / 2}\right) \ell_{\kappa}(I-\rho \hat{a})^{-1}, \\
\widehat{n f l}_{t}^{\Delta \tau}=\hat{\gamma}_{\tau} \hat{\mathbb{E}}_{t} z_{t+1}, & & \hat{\gamma}_{\tau}=\frac{\rho}{1-\rho}\left(\hat{\Lambda}^{1 / 2}-\hat{\Lambda}^{-1 / 2}\right) \ell_{\tau}(I-\rho \hat{a})^{-1}, \quad \text { and } \\
\widehat{n f l}_{t}^{n x}=\hat{\gamma}_{n x} \hat{\mathbb{E}}_{t} z_{t+1}, & & \hat{\gamma}_{n x}=\frac{\rho}{2}\left(\hat{\Lambda}^{1 / 2}+\hat{\Lambda}^{-1 / 2}\right) \ell_{n x}(I-\rho \hat{a})^{-1} . &
\end{array}
$$

The Kalman Filtered estimates of the state vector, $Z_{t \mid t}$, are used to identify agents' expectations, i.e., $\hat{\mathbb{E}}_{t} z_{t+1}=[I, 0] Z_{t \mid t}$. To quantify the overall importance of the trade and valuation channels I then use the identity in (27) to write

$$
\mathbb{V}_{T}\left(n f l_{t}\right)=\mathbb{C V}_{T}\left(\widehat{n f l}_{t}^{\kappa}, n f l_{t}\right)+\mathbb{C V}_{T}\left(\widehat{n f l}_{t}^{\Delta \tau}, n f l_{t}\right)+\mathbb{C V}_{T}\left(\widehat{n f l}_{t}^{n x}, n f l_{t}\right)
$$

where $\mathbb{V}_{T}($.$) and \mathbb{C} \mathbb{V}_{T}(.,$.$) denote the sample variance and covariance, respectively. This expres-$ sion decomposes the sample variance of $n f l_{t}$ into the sum of its covariances with the estimated components. Table 5 reports estimates of these variance contributions as the slope coefficient from regressions of $\widehat{n f l}_{t}^{j}$ on $n f l_{t}$ for $j=\{\kappa, \Delta \tau, n x\} .{ }^{26}$ I also compute 95 percent confidence bands for these estimates using White (1980) standard errors.

The most striking result in Table 5 concerns the variance contribution of the SDF, represented by $\widehat{n f l} l_{t}^{\kappa}$. The model estimates imply that variations in agents' SDF expectations account for 84 percent of the variability in $n f l_{t}$ over the sample. By this metric, the valuation channel appears to be the dominant mechanism of cyclical U.S. external adjustment. Agents' expectations about future trade flows are much less important; revisions in expectations concerning $n x_{t}$ and $\Delta \tau_{t}$ account for roughly ten and six percent of the variations in $n f l_{t}$, respectively.

\footnotetext{
${ }^{26}$ By least squares, the slope coefficient is equal to the ratio $\mathbb{C V}_{T}\left(\widehat{n f l} l_{t}^{j}, n f l_{t}\right) / \mathbb{V}_{T}\left(n f l_{t}\right)$ and so measures the contribution of $\widehat{n f l}_{t}^{j}$ to the variance of $n f l_{t}$.
} 
The right-hand columns show how forecast errors and news shocks contribute to these results. Here I report the relative variance contributions of the forecast errors and news shocks to $n f l_{t}$ and its constituent components. ${ }^{27}$ These statistics show that news shocks are the dominant source of cyclical variations in $N F L_{t} / \mathcal{T}_{t}$. Overall, they contribute approximately 90 percent of the variance. News shocks also appear the dominant driver of the valuation channel, contributing approximately 66 percent of the variance in $\widehat{n f l} l_{t}^{\kappa}$. Together, these results imply that changing expectations about future SDF's are the single most important driver of $n f l_{t}$. Forecast errors play a more important role in the trade channel, contributing approximately 60 percent of the variance in $\widehat{n f l}_{t}^{n x}+\widehat{n f l}_{t}^{\Delta \tau}$. However, the relative unimportance of the trade channel mutes their overall contribution to the cyclical variations in $N F L_{t} / \mathcal{T}_{t}$.

Table 5: Variance Decompositions

\begin{tabular}{|c|c|c|c|c|c|}
\hline & \multirow{2}{*}{$\begin{array}{c}\text { Variance } \\
\text { Contribution }\end{array}$} & \multicolumn{2}{|c|}{ Confidence Band } & \multicolumn{2}{|c|}{ Shock Contributions } \\
\hline & & & & $\Sigma_{e}$ & $\Sigma_{\xi}$ \\
\hline$\widehat{n f l}_{t}^{\kappa}+\widehat{n f l}_{t}^{n x}+\widehat{n f l}_{t}^{\Delta \tau}$ & 1.000 & & & 0.099 & 0.901 \\
\hline$\widehat{n f l} l_{t}^{\kappa}$ & 0.842 & {$[0.613$} & 1.072] & 0.335 & 0.665 \\
\hline$\widehat{n f l} l_{t}^{n x}+\widehat{n f l} l_{t}^{\Delta \tau}$ & 0.157 & {$[-0.072$} & $0.387]$ & 0.597 & 0.403 \\
\hline$\widehat{n f l} l_{t}^{n x}$ & 0.097 & {$[-0.142$} & $0.335]$ & 0.223 & 0.777 \\
\hline$\widehat{n f l}_{t}^{\Delta \tau}$ & 0.061 & 0.050 & $0.071]$ & 0.589 & 0.411 \\
\hline
\end{tabular}

Notes: The table reports the estimated contribution of the $\widehat{n f l}_{t}^{j}$ components to the variance of $n f l_{t}$ together with the 95 percent confidence band. The contributions of the forecast errors and news shocks to the variance of the $\widehat{n f l}_{t}^{j}$ terms are shown in the right-hand columns headed $\Sigma_{e}$ and $\Sigma_{\xi}$, respectively.

The results in Table 5 contrast with those reported by G\&R, who estimate the relative variance contributions of the valuation and trade channels as approximately one and two-thirds, respectively. One reason for this difference arises from the way that cyclical external positions are measured. I use de-trended $N F L_{t} / \mathcal{T}_{t}$ whereas G\&R construct a measure from de-trended

\footnotetext{
${ }^{27}$ I compute the variance decompositions from the implied unconditional variance of the state vector as follows: Equation (24) implies that the estimated covariance matrix for $Z_{t}$, denoted by $\hat{\Omega}$, satisfies $\hat{\Omega}=\hat{A} \hat{\Omega} \hat{A}^{\prime}+\hat{B} \hat{\Sigma} \hat{B}^{\prime}$, where $\hat{A}$ and $\hat{B}$ are the estimates of the $A$ and $B$ matrices and $\hat{\Sigma}$ is the estimated covariance of $U_{t}=\left[e_{t}^{\prime} \quad \xi_{t}^{\prime}\right]^{\prime}$, with $\hat{\Sigma}_{e}$ and $\hat{\Sigma}_{\xi}$ on the leading diagonal block. Let $\left[\begin{array}{cc}e_{t}^{\prime} & 0^{\prime}\end{array}\right]^{\prime}=\ell_{e} U_{t}$ and $\left[\begin{array}{ll}0^{\prime} & \xi_{t}^{\prime}\end{array}\right]^{\prime}=\ell_{\xi} U_{t}$. The contributions of forecast errors and news to the variance of $Z_{t}$ are given by $\hat{\Omega}_{e}$ s.t. $\hat{\Omega}_{e}=\hat{A} \hat{\Omega}_{e} \hat{A}^{\prime}+\hat{B} \ell_{e} \hat{\Sigma} \ell_{e}^{\prime} \hat{B}^{\prime}$, and $\hat{\Omega}_{\xi}$ s.t. $\hat{\Omega}_{\xi}=\hat{A} \hat{\Omega}_{\xi} \hat{A}^{\prime}+\hat{B} \ell_{\xi} \hat{\Sigma} \ell_{\xi}^{\prime} \hat{B}^{\prime}$, respectively. With these matrices I compute the relative contributions of the forecast errors and news shocks to the variance of $n f l_{t}$ by $\left[\begin{array}{ll}\hat{\gamma} & 0\end{array}\right] \hat{\Omega}_{e}\left[\begin{array}{llllll}\hat{\gamma} & 0\end{array}\right]^{\prime} /\left[\begin{array}{llll}\hat{\gamma} & 0\end{array}\right] \hat{\Omega}\left[\begin{array}{ll}\hat{\gamma} & 0\end{array}\right]^{\prime}$ and $\left[\begin{array}{ll}\hat{\gamma} & 0\end{array}\right] \hat{\Omega}_{\xi}\left[\begin{array}{ll}\hat{\gamma} & 0\end{array}\right]^{\prime} /\left[\begin{array}{cc}\hat{\gamma} & 0\end{array}\right] \hat{\Omega}\left[\begin{array}{ll}\hat{\gamma} & 0\end{array}\right]^{\prime}$, respectively. The relative contributions to the variance of the other components are computed in an analogous manner with the estimated vectors $\hat{\gamma}_{j}$ (defined in equation 28) substituting for $\hat{\gamma}$.
} 
foreign assets, liabilities, exports and imports. ${ }^{28}$ These measures have similar cyclical patterns except in the mid-1980's where rising trade deficits produce a sharp deterioration in G\&R's measure of the cyclical position that is not present in de-trended $N F L_{t} / \mathcal{T}_{t}$. I also estimate the contribution of the valuation channel with forecasts of the log SDF rather than the approximate net foreign liability returns used by G\&R. Another reason for the difference in results arises from the choice of estimation method. G\&R compute the valuation and trade components from VAR forecasts (following the C\&S approach). To see what difference this makes, I estimated variation decompositions using $\widehat{n f l}_{t}^{j}$ terms computed from VAR forecasts. I found that the time series of $n f l_{t}$ and $z_{t}$ are well represented by a second-order VAR, and that the cross-equation restrictions cannot be rejected at standard significant levels. ${ }^{29}$ The variance contributions of $\widehat{n f l} l_{t}^{\kappa}$ and $\widehat{n f l}_{t}^{n x}+\widehat{n f l} l_{t}^{\Delta \tau}$ implied by the VAR forecasts are more in line with G\&R's findings, estimated at 45 and 52 percent, respectively. However, when this exercise is repeated with a third-order VAR, the estimated variance contribution of the valuation channel is close to 100 percent. Thus, in this particular context, obtaining robust results concerning the relative importance of the valuation channel from VARs appears a challenge. In contrast, estimating a state space model where $\mathbb{E}_{t} z_{t+1}$ follows a second-order process produces estimates of the variance contributions like those in Table 5. Based on these findings, I conclude that the valuation channel plays a more important role in the external adjustment process for the U.S. than has been established hitherto.

\subsection{The Valuation Channel}

External adjustment via the valuation channel occurs when agents revise their expectations concerning future SDFs. To examine how different shocks affect the U.S. external position via this channel, Figure 3 shows the impulse responses of $\widehat{n f l} l_{t}^{\kappa}$ over a ten-year horizon. ${ }^{30}$ Panel A plots the response to positive, one standard deviation, forecast errors. SDF forecast errors produce very small valuation effects: the error produces a small persistent fall in $\mathbb{E}_{t} \kappa_{t+1}$ that generates a slightly lower value for $n f l_{t}^{\kappa .}$. In contrast, forecast errors in trade and net exports generate significant revisions in agents' SDF expectations and so have much large valuation effects. In particular, a typical positive trade error initially raises the valuation component by

\footnotetext{
${ }^{28}$ The G\&R measure is computed as $n x a_{t}=0.85 \varepsilon_{t}^{a}-0.75 \varepsilon_{t}^{l}+\varepsilon_{t}^{x}-1.1 \varepsilon_{t}^{m}$ where $\varepsilon_{t}^{z}$ for $z=\{a, l, x, m\}$ are the $\log$ deviations of foreign assets, liabilities, exports and imports from their respective trends.

${ }^{29}$ The VAR estimates implies that $\widehat{n f l} l_{t}^{\kappa}+\widehat{n f l} l_{t}^{\Delta \tau}+\widehat{n f l}_{t}^{n x}$ contribute 97 percent of the variance in $n f l_{t}$, with a confidence interval that includes a 100 percent.

${ }^{30}$ Recall that while the model allows for correlations between forecast errors, none of these correlations appear statistically significant. To computing the impulse response functions, I set all the correlations between the errors equal to zero. Impulse responses computed with the aid of the standard Cholesky decomposition of the covariance matrix (with different orderings) produce very similar results.
} 
Figure 3: Value Channel Impulse Responses

A: Forecast Errors

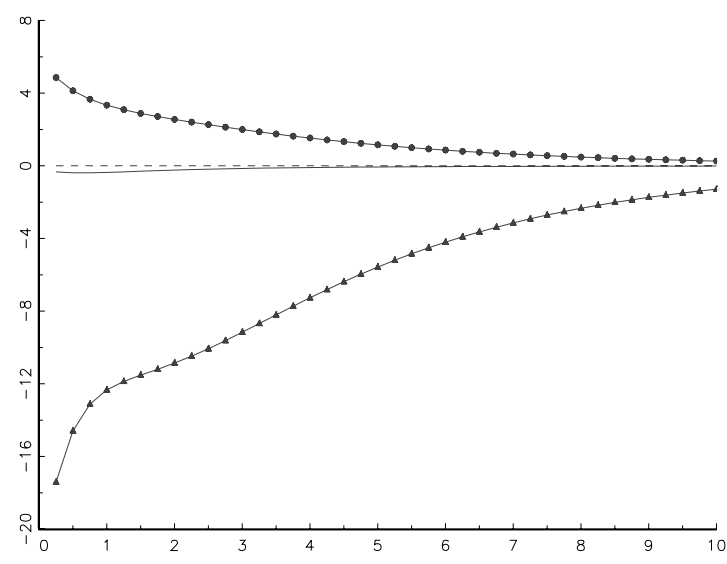

B: News

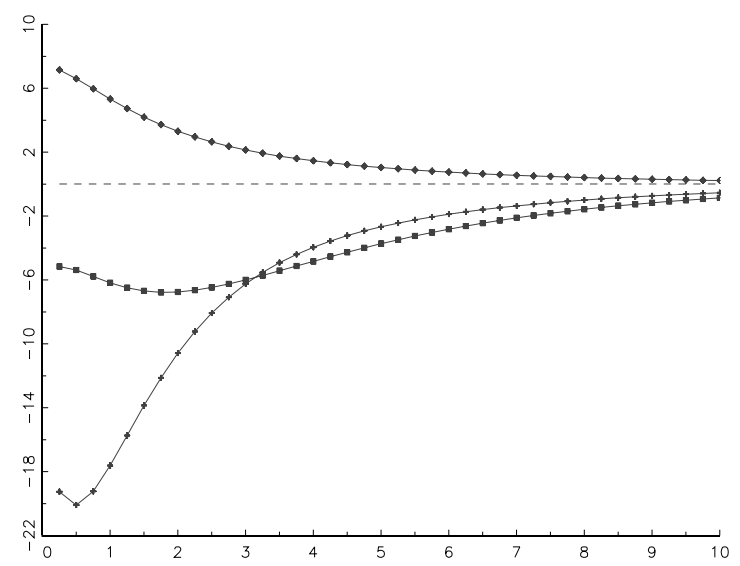

Notes: Graphs show 100 times the impulse response of the valuation component to a one standard deviation shock. Panel A plots responses following a positive financial shock (solid), a shock to trade (solid with bullets) and a shock to net exports (solid with triangles). Panel B plots responses to a positive financial news shock (solid with diamonds), a positive trade news (solid with plus sign) and positive net export news (solid with squares). All impulses are measured over ten years.

five percent, whereas a positive net export error lowers the valuation component by 17.5 percent. Net export errors also appear to have significantly more persistent valuation effects than trade shocks.

Panel B of Figure 3 plots the responses of $\widehat{n f l} l_{t}^{\kappa}$ to the news shocks that change short-term expectations, $\xi_{t}=\left(\mathbb{E}_{t}-\mathbb{E}_{t-1}\right) z_{t+1}$ (so the elements in $\xi_{t}$ represents news concerning $\kappa_{t+1}$, $\Delta \tau_{t+1}$ and $n x_{t+1}$, respectively). ${ }^{31}$ Panel B shows all three shocks produce significant valuation effects. In particular, a one standard deviation shock raising $E_{t} \kappa_{t+1}$ also induces an upward revision in $E_{t} \kappa_{t+h}$ that produces an initial rise in the valuation component of seven percent. In contrast, news that raise $E_{t} \Delta \tau_{t+1}$ and $E_{t} \Delta n x_{t+1}$ produce negative valuation effects. In these cases, the news significantly lowers agents' SDF expectations inducing an initial fall in the valuation component of close to 19 and five percent, respectively.

The plots in Figure 3 show that all but one of the shocks in the model contribute to the dynamics of the U.S. external position via the valuation channel - the notable exception being the shocks that produce the forecast errors in $\kappa_{t}$. Furthermore, these valuation effects appear very persistent, the half-lives of the impulse responses range from approximately two to five years. This means that both anticipated and unanticipated valuation effects contribute to external

\footnotetext{
${ }^{31}$ These impulse responses are computed with the aid of the Cholesky decomposition (to account for the correlations across news) using the variable ordering in $z_{t}$. Changing the ordering of the variables has little material effect on the plots except that the response following trade news is somewhat smaller.
} 
adjustment. ${ }^{32}$ For example, a positive net export forecast error produces a negative unanticipated adjustment followed by a positive anticipated adjustment. Overall, the model estimates imply that anticipated adjustments account for a higher fraction of the change in $n f l_{t}^{\kappa}$ over longer horizons; ranging from four percent of the variance at a quarter to 20 percent at three years.

The valuation channel operates via capital gains and losses on foreign asset holdings, liability holdings, or some combination of the two. To study these effects, consider the price of a claim to the cash flows generated by the asset and liability positions. Following Campbell and Shiller (1988), we can approximate the log price of such a claim by

$$
p_{t}=\text { const. }+d_{t}+\mathbb{E}_{t} \sum_{j=1}^{\infty} \delta^{j}\left(\Delta d_{t+j}-r_{t+j}^{\mathrm{TB}}-e r_{t+j}\right),
$$

where $d_{t}$ is the log dividend paid by the claim, and $\delta=1 /(1+D / P)<1$ with $D / P$ equal to the long-run dividend-price ratio. Importantly, this (approximate) identity holds for a claim on the cash flows generated by holdings of foreign assets, liabilities or even portions of these portfolios, such as equity assets. It implies that changes in $p_{t}$, representing capital gains/losses, must either reflect changes in current dividends, $d_{t}$, revisions in expectations concerning future dividend growth $\Delta d_{t+j}$, T-bill returns $r_{t+j}^{\mathrm{TB}}$, and/or excess returns $e r_{t+j}$. Moreover, if revisions in agents' expectations $\mathbb{E}_{t} \kappa_{t+j}$ are only correlated with $\mathbb{E}_{t} r_{t+j}^{\mathrm{TB}}$, the valuation channel will produce capital gains and losses across foreign asset and liability holdings because the prices of claims to both assets and liabilities depend on $\mathbb{E}_{t} r_{t+j}^{\mathrm{TB}}$. Alternatively, revisions in $\mathbb{E}_{t} \kappa_{t+j}$ may be only correlated with expected excess returns on a particular class of asset/liability, like equity assets, so the capital gains/losses produced by the valuation channel would be concentrated in a subset of the country's asset/liability holdings.

To assess the size of the capital gains produced by the valuation channel across different assets and liability holdings, Table 6 reports estimates from the forecasting regression:

$$
\sum_{i=1}^{h} e r_{t+i}=\phi_{0}+\phi_{1} \widehat{n f l_{t}^{\kappa}}+\varepsilon_{t+h}
$$

for excess returns $e r_{t}$ and horizons $h=\{4,8,20\}$ quarters. The logic behind this regression is straightforward. Suppose that the valuation channel works only through capital gains and losses on foreign assets. In this case, there should be a positive slope coefficient in the regression for

\footnotetext{
${ }^{32}$ If we combine the identity $\Delta n f l_{t+1}^{\kappa}=\mathbb{E}_{t} \Delta n f l_{t+1}^{\kappa}+n f l_{t+1}^{\kappa}-\mathbb{E}_{t} n f l_{t+1}^{\kappa}$ with the definition of $n f l_{t}^{\kappa}$, we can write change in the valuation component as $\Delta n f l_{t+1}^{\kappa}=\eta \mathbb{E}_{t} \sum_{i=2}^{\infty} \rho^{i-1} \Delta \kappa_{t+i}+\left(\mathbb{E}_{t+1}-\mathbb{E}_{t}\right) \eta \sum_{i=2}^{\infty} \rho^{i-1} \kappa_{t+i}$. The first term on the right identifies anticipated adjustments due to expected future changes in the SDF while the second identifies unanticipated adjustments driven by revisions in expectations concerning the future SDF. Figure 3 shows that most shocks produce both effects.
} 


\section{Table 6: Excess Returns}

\begin{tabular}{|c|c|c|c|c|c|c|c|c|}
\hline \multirow[b]{2}{*}{ Return } & & \multirow{2}{*}{$\begin{array}{c}\text { Mean } \\
\text { (i) }\end{array}$} & \multicolumn{2}{|c|}{1 Year } & \multicolumn{2}{|c|}{2 Years } & \multicolumn{2}{|c|}{5 Years } \\
\hline & & & $\phi_{1}$ & $R^{2}$ & $\phi_{1}$ & $R^{2}$ & $\phi_{1}$ & $R^{2}$ \\
\hline \multirow[t]{5}{*}{ Assets } & All & $\begin{array}{c}1.047 \\
(0.906)\end{array}$ & $\begin{array}{l}2.788^{* * *} \\
(0.957)\end{array}$ & 0.083 & $\begin{array}{l}2.055^{* * *} \\
(0.914)\end{array}$ & 0.096 & $\begin{array}{c}0.862 \\
(0.646)\end{array}$ & 0.071 \\
\hline & Equity & $\begin{array}{c}4.163^{* *} \\
(2.026)\end{array}$ & $\begin{array}{l}7.157^{* * *} \\
(1.984)\end{array}$ & 0.108 & $\begin{array}{l}4.546^{* * *} \\
(1.566)\end{array}$ & 0.088 & $\begin{array}{c}1.241 \\
(0.949)\end{array}$ & 0.024 \\
\hline & FDI & $\begin{array}{c}2.160 \\
(1.852)\end{array}$ & $\begin{array}{l}5.574^{* * *} \\
(1.859)\end{array}$ & 0.080 & $\begin{array}{c}3.862^{* *} \\
(1.603)\end{array}$ & 0.088 & $\begin{array}{c}1.293 \\
(1.053)\end{array}$ & 0.042 \\
\hline & Debt & $\begin{array}{l}1.020 \\
(0.712)\end{array}$ & $\begin{array}{c}0.226 \\
(0.796)\end{array}$ & 0.001 & $\begin{array}{l}0.045 \\
(0.653)\end{array}$ & 0.001 & $\begin{array}{c}0.059 \\
(0.475)\end{array}$ & 0.001 \\
\hline & Other & $\begin{array}{c}0.127 \\
(0.189)\end{array}$ & $\begin{array}{l}0.561^{* * *} \\
(0.194)\end{array}$ & 0.082 & $\begin{array}{l}0.513^{* * *} \\
(0.189)\end{array}$ & 0.131 & $\begin{array}{c}0.234^{*} \\
(0.131)\end{array}$ & 0.084 \\
\hline \multirow[t]{5}{*}{ Liabilities } & All & $\begin{array}{c}1.184^{* *} \\
(0.635)\end{array}$ & $\begin{array}{l}-0.832 \\
(0.713)\end{array}$ & 0.016 & $\begin{array}{l}-0.938 \\
(0.655)\end{array}$ & 0.040 & $\begin{array}{l}-0.500 \\
(0.455)\end{array}$ & 0.035 \\
\hline & Equity & $\begin{array}{c}4.021^{* *} \\
(2.149)\end{array}$ & $\begin{array}{l}-1.176 \\
(2.015)\end{array}$ & 0.003 & $\begin{array}{l}-1.746 \\
(1.695)\end{array}$ & 0.015 & $\begin{array}{l}-1.329 \\
(1.160)\end{array}$ & 0.029 \\
\hline & FDI & $\begin{array}{c}1.905 \\
(1.537)\end{array}$ & $\begin{array}{l}-0.770 \\
(1.454)\end{array}$ & 0.003 & $\begin{array}{l}-1.234 \\
(1.242)\end{array}$ & 0.015 & $\begin{array}{l}-0.923 \\
(0.830)\end{array}$ & 0.028 \\
\hline & Debt & $\begin{array}{c}0.604 \\
(0.816)\end{array}$ & $\begin{array}{l}-0.845 \\
(0.815)\end{array}$ & 0.012 & $\begin{array}{l}-0.724 \\
(0.623)\end{array}$ & 0.019 & $\begin{array}{l}-0.220 \\
(0.560)\end{array}$ & 0.005 \\
\hline & Other & $\begin{array}{l}-0.035 \\
(0.020)\end{array}$ & $\begin{array}{c}0.019 \\
(0.023)\end{array}$ & 0.008 & $\begin{array}{c}0.019 \\
(0.024)\end{array}$ & 0.014 & $\begin{array}{l}-0.015 \\
(0.015)\end{array}$ & 0.016 \\
\hline$r^{\mathrm{TB}}$ & & $\begin{array}{l}1.254^{* * *} \\
(0.155)\end{array}$ & $\begin{array}{l}-0.792 \\
(0.271)\end{array}$ & 0.094 & $\begin{array}{l}-0.725 \\
(0.321)\end{array}$ & 0.092 & $\begin{array}{l}-0.523 \\
(0.284)\end{array}$ & 0.072 \\
\hline$\Delta \ln \mathcal{E}$ & & $\begin{array}{l}-0.339 \\
(0.613)\end{array}$ & $\begin{array}{l}-2.850^{* *} \\
(0.609)\end{array}$ & 0.171 & $\begin{array}{l}-2.412^{* *} \\
(0.593)\end{array}$ & 0.202 & $\begin{array}{l}-1.123^{* *} \\
(0.544)\end{array}$ & 0.085 \\
\hline
\end{tabular}

Notes: Column (i) reports the mean log excess return for US assets, liabilities, and the mean return on T-bills, $r^{\mathrm{TB}}$ and the $\log$ change in the real effective exchange rate, $\Delta \ln \mathcal{E}$. Asymptotic, heteroskedastic consistent standard errors are shown in parenthesis. Columns (ii) - (vii) report the slope coefficients and $R^{2}$ statistics from regression of the future excess return differentials, on $\widehat{n f l} l_{t}^{\kappa}$ where returns are computed over one, two and five year horizons. Asymptotic standard errors that allow for heteroskedasticity and the forecast overlap are shown in parenthesis below the parameter estimates. "***", "**" and "** denote statistical significance at the 1,5 and 10 percent levels, respectively.

excess asset returns and a zero slope in the regression for excess liability returns. Intuitively, a rise (fall) in $\widehat{n f l}_{t}^{\kappa}$ should forecast higher (lower) future excess returns because agents' expectations $\mathbb{E}_{t} e r_{t+j}$ must rise (fall) to produce the capital loss (gain) on assets (see equation 30). Conversely, the slope coefficient will be negative in the regression for excess liability returns and zero in the regression for excess asset returns if the valuation channel works only through capital gains and 
losses on foreign liabilities.

The results in Table 6 show a consistent pattern. The table shows that $\widehat{n f l} l_{t}^{\kappa}$ has significant forecasting power for future excess returns across almost all classes of foreign assets over horizons of one and two years. Moreover, the slope coefficients are uniformly positive. In contrast, $\widehat{n f l} l_{t}^{\kappa}$ has little forecasting power for excess liability returns. None of the slope coefficients is statistically significant at standard levels. In addition, the last lines of the table report the results from regressing future T-bill returns and real depreciation rates on $\widehat{n f l} l_{t}^{\kappa}$. Here we see that $\widehat{n f l} l_{t}^{\kappa}$ only has significant forecasting power for the real depreciation rate (particular at the one and two-year horizon). Ceteris paribus, a depreciation of the dollar (i.e. a fall in $\mathcal{E}_{t}$ ) increases the excess return on U.S. foreign assets denominated in foreign currency, so these forecasting results complement those for excess asset returns.

Overall, the estimates in Table 6 show that external adjustment through the valuation channel takes place primarily via capital gains and losses on U.S. foreign assets. Relatedly, G\&R found that forecasts of excess returns on foreign assets produced more adjustment via the valuation channel than forecasts of excess returns on foreign liabilities. My analysis explains their finding in terms of agents' expectations concerning the SDF and their implications for capital gains and losses on foreign assets. G\&R also examined the link between cyclical external positions and depreciation rates, showing that an improvement in the cyclical external position forecasts an appreciation of the dollar. Here changes in the valuation component are the dominant driver of cyclical changes in external positions, so $\widehat{n f l} l_{t}^{\kappa}$ has similar forecasting power for depreciation rates.

These results represent a challenge to existing theoretical models of external adjustment. Gourinchas and Rey (2013) and Coeurdacier and Rey (2012) note that many existing models are unable to produce sizable variations in the expected excess returns. For example, in Pavlova and Rigobon (2008), Tille and van Wincoop (2010) and Devereux and Sutherland (2010) capital gains and losses on foreign assets and liabilities reflect news concerning future "dividends" as opposed to changing expectations about future excess returns, so their predictions are at odds with the empirical results in Table 6 . Variations in the expected excess returns play a larger role in Evans (2014) because changes in investors' risk aversion alter the equilibrium risk premia on foreign assets and liabilities. The predictions of this model are closer to the empirical findings reported above, but they do not explain why the U.S. valuation channel appears to operate primarily through gains and losses on foreign assets. 
Figure 4: Trade Channel Impulse Responses

A: Shocks

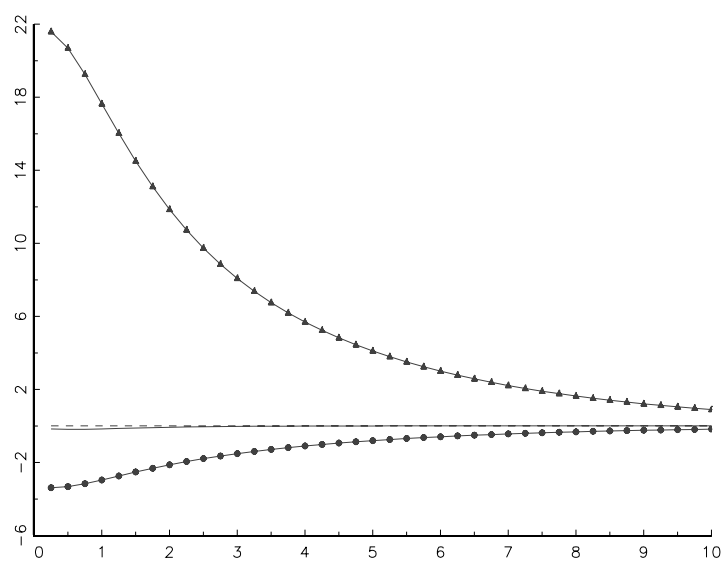

B: News

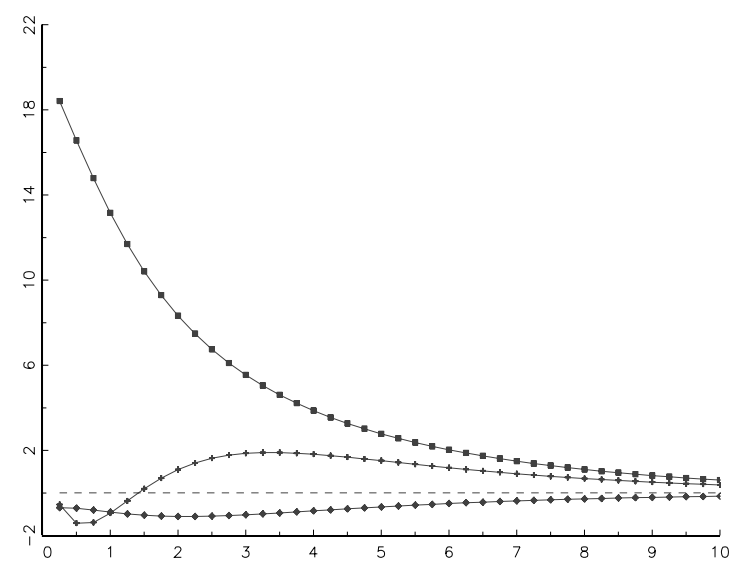

Notes: Graphs show 100 times the impulse response of the trade component to a one standard deviation shock. Panel A plots responses following a positive financial shock (solid), a shock to trade (solid with bullets) and a shock to net exports (solid with triangles). Panel B plots responses to a positive financial news shock (solid with diamonds), a positive trade news (solid with plus sign) and positive net export news (solid with squares). All impulses are measured over ten years.

\subsection{The Trade Channel}

Figure 4 shows how different shocks affect the U.S. external position via the trade channel. Here I plot responses of the estimated trade component (i.e., $\widehat{n f l}_{t}^{\Delta \tau}+\widehat{n f l}_{t}^{n x}$ ) to positive, one standard deviation, forecast errors and news shocks. ${ }^{33}$ Panel A shows that only net export and trade forecast errors produce sizable adjustments. In particular, positive net export errors produce a large initial increase in the trade component because they induce an upward revision in $\mathbb{E}_{t} n x_{t+i}$. Thereafter, expectations for future net exports fall generating a prolonged decline in the trade component towards zero. In contrast, positive trade errors have a small negative effect because they induce a modest rise in $\mathbb{E}_{t} \Delta \tau_{t+i}$ that is overwhelmed by a fall in $\mathbb{E}_{t} n x_{t+i}$. Panel B tells a similar story. Here positive net export news has the largest and most persistent impact on the trade component, whereas SDF and trade news have comparatively minor effects. The importance of net export news is consistent with the mechanism driving the U.S. current account described in Engel and Rogers (2006), which I discuss below.

The estimated model identifies variations in the trade component from changing expectations concerning the future net export ratio, $n x_{t}$, rather than exports and imports individually. To examine whether information concerning exports and imports affect the trade component

\footnotetext{
${ }^{33}$ These responses are computed in the same manner as the plots in Figure 3.
} 
Table 7: Forecasting Trade Flows

\begin{tabular}{|c|c|c|c|c|c|c|c|}
\hline & \multirow[b]{2}{*}{ Forecast } & \multicolumn{2}{|c|}{1 Year } & \multicolumn{2}{|c|}{2 Years } & \multicolumn{2}{|c|}{5 Years } \\
\hline & & $\begin{array}{l}\phi_{1} \\
\text { (i) }\end{array}$ & $\begin{array}{l}R^{2} \\
\text { (ii) }\end{array}$ & $\begin{array}{c}\phi_{1} \\
\text { (iii) }\end{array}$ & $\begin{array}{l}R^{2} \\
\text { (iv) }\end{array}$ & $\begin{array}{l}\phi_{1} \\
(\mathrm{v})\end{array}$ & $\begin{array}{l}R^{2} \\
\text { (vi) }\end{array}$ \\
\hline \multirow[t]{2}{*}{ A: } & $n x_{t}$ & $\begin{array}{l}57.147^{* * *} \\
(8.725)\end{array}$ & 0.334 & $\begin{array}{c}51.470^{* * *} \\
(11.531)\end{array}$ & 0.277 & $\begin{array}{c}38.320^{* *} \\
(15.115)\end{array}$ & 0.170 \\
\hline & $\Delta \tau_{t}$ & $\begin{array}{l}-1.103 \\
(0.748)\end{array}$ & 0.011 & $\begin{array}{l}-0.620 \\
(0.658)\end{array}$ & 0.007 & $\begin{array}{c}0.622 \\
(0.444)\end{array}$ & 0.026 \\
\hline \multirow[t]{2}{*}{ B: } & $x_{t}$ & $\begin{array}{l}12.770^{*} \\
(7.219)\end{array}$ & 0.028 & $\begin{array}{c}9.202 \\
(8.848)\end{array}$ & 0.016 & $\begin{array}{c}9.659 \\
(9.845)\end{array}$ & 0.021 \\
\hline & $m_{t}$ & $\begin{array}{c}-34.399^{* *} \\
(7.238)\end{array}$ & 0.174 & $\begin{array}{c}-29.982^{* *} \\
(8.873)\end{array}$ & 0.142 & $\begin{array}{l}-10.300 \\
(10.682)\end{array}$ & 0.020 \\
\hline C: & $y_{t}$ & $\begin{array}{l}-3.053^{* * *} \\
(0.657)\end{array}$ & 0.148 & $\begin{array}{l}-2.538^{* * *} \\
(0.690)\end{array}$ & 0.160 & $\begin{array}{l}-0.492 \\
(0.465)\end{array}$ & 0.033 \\
\hline & $\Delta \ln \left(Y_{t}\right)$ & $\begin{array}{c}0.188 \\
(0.286)\end{array}$ & 0.003 & $\begin{array}{c}0.695^{* *} \\
(0.277)\end{array}$ & 0.076 & $\begin{array}{l}0.910^{* * *} \\
(0.220)\end{array}$ & 0.350 \\
\hline
\end{tabular}

Notes: The table reports slope coefficients and $R^{2}$ statistics from regression of future trade flows/gdp growth on $\widehat{n f l}_{t}^{\Delta \tau}+\widehat{n f l}_{t}^{n x}$ where the future flows are computed over one, two and five year horizons. Asymptotic standard errors that allow for heteroskedasticity and the forecast overlap are shown in parenthesis below the parameter estimates. "***", "**" and "** denote statistical significance at the 1, 5 and 10 percent levels, respectively.

symmetrically, Table 7 reports the estimates from forecasting regressions of the form:

$$
\frac{1}{h} \sum_{i=1}^{h} \mathscr{X}_{t+i}=\phi_{0}+\phi_{1}\left(\widehat{n f l}_{t}^{\Delta \tau}+\widehat{n f l}_{t}^{n x}\right)+\varepsilon_{t+h}
$$

for horizons $h=\{4,8,20\}$ quarters. Panel A shows results when the forecast variable $\mathscr{X}_{t}$ is the net export ratio, $n x_{t}$, and trade growth, $\Delta \tau_{t}$. Since the trade component is constructed from estimates of agent's expectations concerning $n x_{t}$ and $\Delta \tau_{t}$, we should find some forecasting power for both variables if agents expectations are informative. This appears to be so in the case of net exports. All the slope coefficients are positive and statistically significant across the three horizons. Moreover, the $R^{2}$ statistics indicate that the expectations embedded in the trade component contain an economically significant amount of information about future net exports. By contrast, the expectation concerning trade growth appear to be quite uninformative; none of the slope coefficients is significant and the $R^{2}$ statistics are small across all horizons.

Panel B reports on the forecasting power of the trade component for future cyclical flows of 
exports and imports. Here we see that the trade component has substantially more forecasting power for the future imports than exports over horizons of one and two years; the slope coefficients in the import regressions are statistically significant and the $R^{2}$ statistics are a good deal higher than their counterparts in the export regressions. These results suggest that agents' short-term expectations concerning net exports are more informative about imports than exports while at longer horizons they are informative about the difference between exports and imports rather than the individual series.

Under the intertemporal approach to the current account, a country's external position should deteriorate (improve) when shocks temporarily reduce (raise) output relative to its long-run path. The regression estimates in Panel C shed light on this prediction of consumption smoothing. The first row shows that the trade component has significant forecasting power for future deviations of log GDP from its long-run trend (identified by the H-P filter) over one- and two-year horizons, $y_{t}$. In particular the negative slope coefficients imply that a current rise in the trade component anticipates lower levels of GDP relative to its long-run trend, consistent with the intertemporal approach. The last row presents the regression estimates when GDP growth $\Delta \ln \left(Y_{t}\right)$ is the forecast variable. Here the $R^{2}$ statistics show that forecasting power increases substantially with the horizon. In this case, a rise in the trade component forecasts a significant increase in GDP growth over the next two-to-five years. These findings are also consistent with the intertemporal approach insofar as temporarily low GDP relative to trend should be followed by persistently higher GDP growth than temporarily high GDP relative to trend..$^{34}$

I also examined two variants for the forecasting regression in (31). The first added current and past lags of the flow variable to the right-hand-side. The estimated coefficients on the trade component are similar to those in Table 7 when two flows are included, but statistical significance declines as additional lagged flows are added. The second variant used $n f l_{t}$ as the forecasting variable rather than the trade component. These regressions produced very different results. Cyclical movements in $N F L_{t} / \mathcal{T}_{t}$ had no statistically significant forecasting power for $n x_{t}, x_{t}, m_{t}, y_{t}$ and $\Delta \ln \left(Y_{t}\right)$, and only marginal forecasting power for $\Delta \tau_{t}$ at the two- and fiveyear horizons. Thus, it appears that variations in the valuation component mask the forecasting power of the trade component for future trade flows and GDP.

These results are consistent with the $\mathrm{C} \& \mathrm{~K}$ finding that transitory shocks drive changes in

\footnotetext{
${ }^{34}$ To see this more formally, suppose that GDP growth follows: $\Delta \ln \left(Y_{t}\right)=g+\Delta y_{t}+u_{t}$ with $y_{t}=\phi y_{t-1}+\nu_{t}$ where $u_{t}$ and $v_{t}$ are mean-zero i.i.d. shocks and $0<\phi<1$. Then $\frac{1}{h} \sum_{i=1}^{h} y_{t+i}=\frac{\phi}{h}\left(\frac{1-\phi^{h-1}}{1-\phi}\right) y_{t}+\zeta_{t+h}^{1}$ and $\frac{1}{h} \sum_{i=1}^{h} \Delta \ln \left(Y_{t+i}\right)=g-\frac{1}{h}\left(1-\phi^{h-1}\right) y_{t}+\zeta_{t+h}^{2}$ where $\zeta_{t+h}^{i}$ are forecast errors. Under these circumstances it is easy to check that the estimated slope coefficients from regressions of $\frac{1}{h} \sum_{i=1}^{h} y_{t+i}$ and $\frac{1}{h} \sum_{i=1}^{h} \Delta \ln \left(Y_{t+i}\right)$ on $\widehat{n f l}_{t}^{\Delta \tau}+\widehat{n f l}_{t}^{n x}$ will be negative and (respectively) positive when $\operatorname{corr}\left(y_{t}, \widehat{n f l} l_{t}^{\Delta \tau}+\widehat{n f l} l_{t}^{n x}\right)<0$, consistent with the intertemporal approach.
} 
the U.S. net external position. The forecasting power of the trade component for future net exports is also in line with the findings in G\&R. Their estimates of the trade and valuation components that comprise the cyclical external position are positively correlated, so the external position has similar forecasting power for future trade flows as the trade component. In contrast, the trade and valuation components estimated here are negatively correlated, so the forecasting power of the trade component is masked by the valuation component when the external position is used to forecast trade flows and GDP. In addition, my results shed light on the mixed findings reported in the early literature examining the intertemporal model of the current account noted by Obstfeld and Rogoff (1995). If changes in the external position reflect both valuation and trade adjustments (that partially offset one another), position changes can appear unrelated to the empirical predictions of the intertemporal approach when in fact changes in the trade component are substantially consistent with the model.

\section{Historical Perspective}

In this final section, I use the model estimates to examine the behavior of the U.S. external position over the sample. In so doing I address several issues posed by recent literature on global imbalances.

\section{Figure 5: Historical Paths for the Trade and Valuation Components}

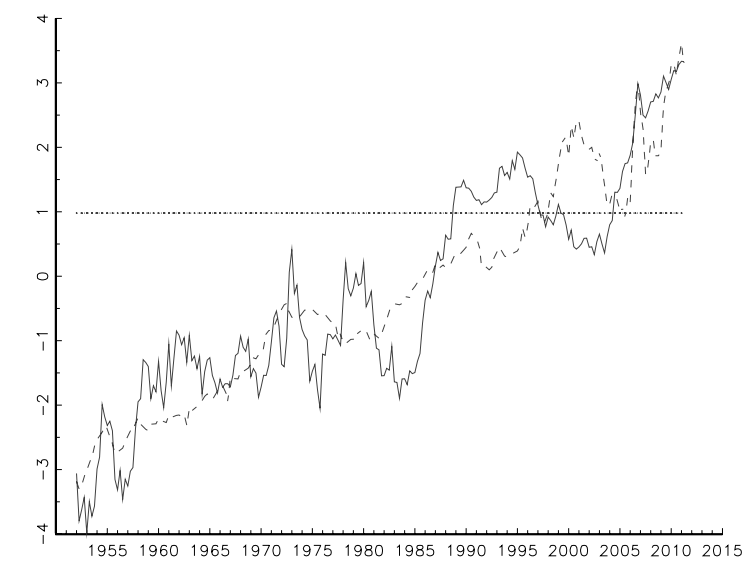

A: Key: $\overline{n f l}_{t}+\widehat{n f l}_{t}^{\Delta \tau}+\widehat{n f l}_{t}^{n x}$ (solid) and $N F L_{t} / \mathcal{T}_{t}$ (dashed). Steady-state value for $N F L_{t} / \mathcal{T}_{t}$ (horizontal line).

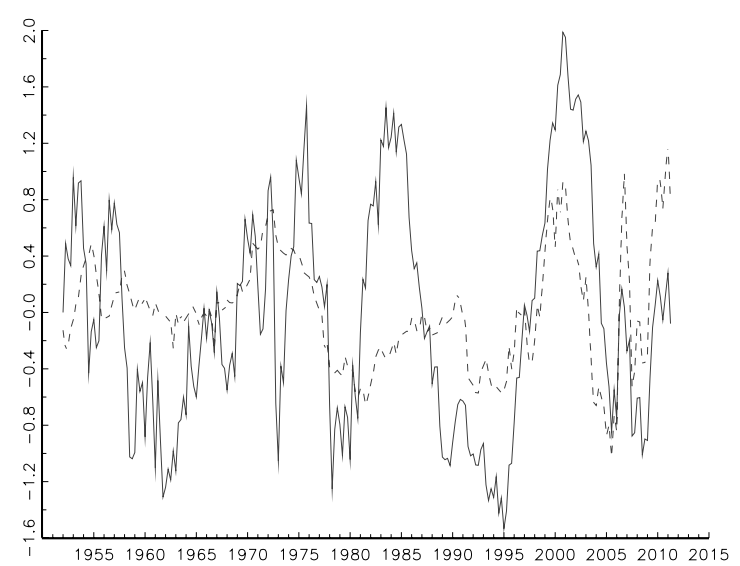

B: Key: $\widehat{n f l}_{t}^{\kappa}$ (solid) and $n f l_{t}$ (dashed).

Figure 5 provides an overview of how the trade and valuation channels contributed to the evolution of the U.S. external position over the past 60 years. Panel A plots $N F L_{t} / \mathcal{T}_{t}$ and the sum of the secular and cyclical trade components: $\overline{n f l}_{t}+\widehat{n f l}_{t}^{\Delta \tau}+\widehat{n f l}_{t}^{n x}$, while panel B plots 
the cyclical portion of $N F L_{t} / \mathcal{T}_{t}$ and the valuation component, $\widehat{n f l}_{t}^{\kappa}$. Several features stand out. First, the plots show that while adjustment via the valuation channel has been substantial over short- and medium-term horizons, it has not been an important contributor to long-term deterioration in the U.S. external position. For example, between 1980 and 2005 the amplitude of the swings in the valuation component are close to 2.5 times total trade, but the increase in $N F L_{t} / \mathcal{T}_{t}$ and the trade components are approximately equal. Second, the swings in the valuation component were generally larger that the swings in $n f l_{t}$ because the trade and valuation channels had offsetting effects. Third, it is surprising to see that the changes in the valuation component in 2008-9 are no larger than the changes at other times in the sample. Although this period witnessed the height of the most severe financial crisis since the 1930's, the variations in the valuation component are quite unremarkable.

Figure 5 also identifies the steady state value for $N F L_{t} / \mathcal{T}_{t}$ by the horizontal dotted line in Panel A. This estimate of 0.982 is computed from the implied steady state of $\rho\left(\Lambda^{1 / 2}-\Lambda^{-1 / 2}\right) /(1-$ $\rho$ ) using the estimates of $\rho$ and $\Lambda$ in Table 4. By the end of the sample period, the (H-P filtered) trend in the trade-to-GDP ratio is approximately 0.15 , so this estimate implies a value for the NFL position close to 15 percent of GDP. Clearly, the persistent rise in $N F L_{t} / \mathcal{T}_{t}$ over the past 60 years represents a movement towards and then away from the steady state.

\subsection{Sustainability}

The question of whether the prolonged deterioration in the U.S. external position represents an adjustment along a sustainable path or is the precursor to an abrupt change accompanied by a crisis has been the subject of much debate in the literature. One side of the debate sees the persistent rise in the NFL position (current account deficits) as unsustainable because eventually the interest of the NFL position would exceed GDP (see, e.g., Summers, 2004, Obstfeld and Rogoff, 2007, and others, summarized in Backus et al., 2009). The other side argues that current account deficits are sustainable because the U.S. financial system has a comparative advantage in supplying high-quality assets (see, e.g., Caballero, Farhi, and Gourinchas, 2008, Mendoza, Quadrini, and Rios-Rull, 2009 and Caballero and Krishnamurthy, 2009, among others). Here I consider two implications of the model's estimates that are relevant to this debate.

The first implication concerns the determination of the steady-state value for $N F L_{t} / \mathcal{T}_{t}$. As I noted above, a country can be steady-state debtor (or creditor) if it runs a trade surplus (or deficit), but the size of the steady-state position depends, in part, on the (long-run) expected $\mathrm{SDF}, \kappa=\mathbb{E} \kappa_{t}$. My estimate for $\kappa$ is based on average returns and so reflect differences between the average asset and liability returns in each class. These differences are small (see Table 1), but 
they have a measurable effect. If $\kappa$ is re-estimated using the average of asset and liability returns in each class, the implied value for $\rho$ is 0.948 and the steady-state value for $N F L_{t} / \mathcal{T}_{t}$ becomes 0.793, which is equivalent to $11.9 \%$ of GDP. Thus, differences between the average returns on assets and liabilities raise the steady state NFL level by approximately three percent of GDP. In this sense, the "Exorbitant Privilege" enjoyed by the U.S. in financial markets allows it to sustain a slightly higher steady-state debt level.

The second implication concerns the persistent rise in $N F L_{t} / \mathcal{T}_{t}$ over the past 60 years. This long-term deterioration in the U.S. external position primarily reflects the rise in the secular component

$$
\overline{n f l}_{t}=\eta \rho+\psi \mathbb{E}_{t} \sum_{i=1}^{\infty} \rho^{i}\left[\overline{n x}_{t+i}-\lambda\right],
$$

so it must also reflect rising expectations about the secular path for the net export ratio, $\mathbb{E}_{t} \overline{n x}_{t+i}$. More specifically, the persistent increase in $N F L_{t} / \mathcal{T}_{t}$ beyond its steady state level in the last decade must reflect expectations that $\mathbb{E}_{t} \overline{n x}_{t+h}>\lambda$ for some finite horizons $h$ if the U.S. external position is sustainable. In other words, sustainability requires that agents are optimistic about the medium-term behavior of the net export ratio.

\section{Figure 6: Trade Expectations}

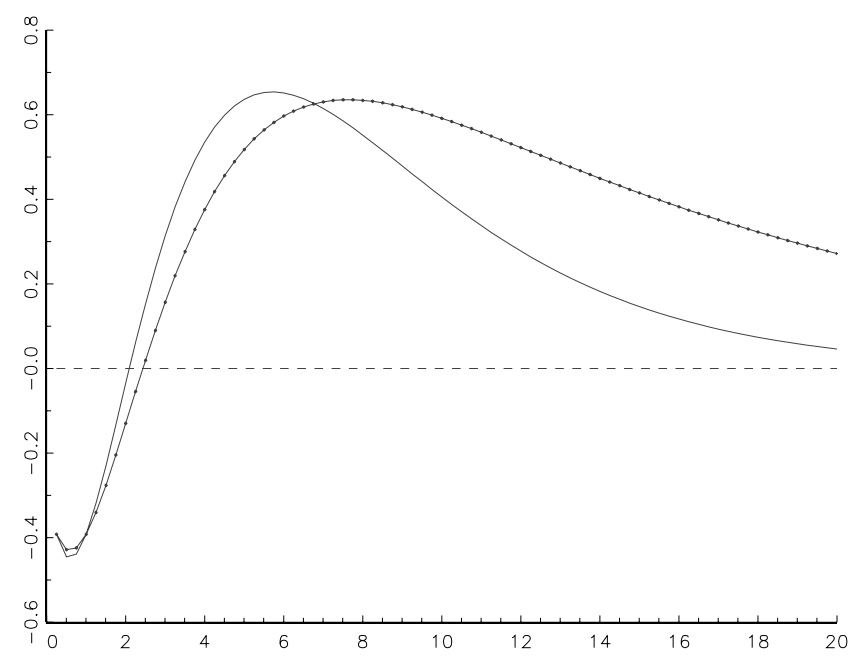

The figure plots two paths for expectations: $\mathbb{E}_{t} \overline{n x}_{t+i}-\lambda$ against horizon $i$ (measured in years) conditioned on the value for $\lambda-\overline{n x}_{t}$ at the end of the sample, consistent with the secular trends, $\overline{n f l}_{t}$ and $\overline{n x}_{t}$.

To see just how optimistic they must be, Figure 6 plots two possible paths for expectations, $\mathbb{E}_{t} \overline{n x}_{t+i}-\lambda$, in 2013:IV that are consistent with the levels of $\overline{n f l}_{t}$ and $\overline{n x}_{t} \cdot{ }^{35}$ Both paths start

\footnotetext{
${ }^{35}$ The paths in Figure 6 are computed by assuming that expectations take the form: $\mathbb{E}_{t} \overline{n x}_{t+i}-\lambda=$ $\sum_{j=1}^{3} \pi_{j} \phi_{j}^{i}\left(\lambda-\overline{n x}_{t}\right)$ and finding values for $\pi_{j}$ and $\phi_{j} \in[0,1]$ such that $\overline{n f l}_{t}-\eta \rho=\psi \mathbb{E}_{t} \sum_{i=1}^{\infty} \rho^{i}\left[\overline{n x}_{t+i}-\lambda\right]=$ $-11.44\left(\overline{n x}_{t}-\lambda\right)$.
} 
near -0.4 , the estimated value for $\overline{n x}_{t}-\lambda$ in 2013:IV. They then rise above zero within two years, peaking at approximately 0.6 between six to eight years, before slowly falling back towards zero. These paths demonstrate that it is possible to simultaneously reconcile the high value for $N F L_{t} / \mathcal{T}_{t}$ and low level for $N X_{t}$ in 2013:IV with the view that the U.S. external position is indeed sustainable. However, to do so, agents must hold expectations for future net exports that are without precedent in the last 60 years (see Figure 1). ${ }^{36}$ This analysis reinterprets the so-called consensus view (exemplified by the arguments in Summers, 2004, Obstfeld and Rogoff, 2007, Backus et al., 2009 and others) that current account deficits cannot go on forever. Eventually, either net exports must improve in line with agents' expectations, and/or agents' expectations will adjust to be consistent with the historical behavior of net exports. ${ }^{37}$ It is also quite distinct from the work of Engel and Rogers (2006). They argue that the deterioration in the U.S. current account between 1998 and 2004 can be largely attributed to forecasts of rising U.S. growth relative to other advanced countries. Figure 2 shows that the cyclical component of the net export ratio, $n x_{t}$, exhibits cycles lasting approximately a decade since the 1980s, so the current account dynamics studied by Engel and Rogers (2006) are (mostly) captured by the cyclical dynamics of the model. ${ }^{38}$ By excluding cyclical dynamics, my analysis here focuses on a much lower frequency phenomena.

Bernanke (2005) argued that financial markets in emerging market countries were insufficiently developed to accommodate the rise in desired global saving that began in the mid-1990's, producing a global savings glut that contributed to the deterioration in the U.S. external position. Caballero, Farhi, and Gourinchas (2008) formalize this idea in a model where the U.S. has a comparative advantage in the creation of financial assets from real investments that act as stores of value (see, also Gourinchas and Rey, 2013). In these models the savings glut is associated with

\footnotetext{
${ }^{36}$ There are other paths for expectations consistent with the levels of $\overline{n f l}_{t}$ and $\overline{n x}_{t}$ at the end of the sample, but experiments show that it is impossible to find expectations where $\lim _{i \rightarrow \infty} \mathbb{E}_{t} \overline{n x}_{t+i}=\lambda$ if it takes much more than two years before $\mathbb{E}_{t} \overline{n x}_{t+i}>\lambda$. In this sense, the plots in Figure 6 are representative. They also appear robust to the exact value for $\rho$. I obtain very similar plots using $\rho=0.949$, the value implied by the absence of the "Exorbitant Privilege" (see above). Zucman (2013) argues that the official IIP statistics overstate the true U.S. NFL position because sizable U.S. foreign asset holdings are held offshore. The "true" NFL position implied by his estimates give the U.S. a little more leeway than my calculations based on the IIP data, but they do not eliminate the need for unprecedented future net exports to keep the external position on a sustainable path.

${ }^{37}$ The U.S. could still have a substantial NFL position after such an adjustment. Backus, Cooley, and Henriksen (2014) show how differences in the demographic trends between the U.S. and other major countries can produce savings and investment flows that account for roughly half of the secular rise in the U.S. $N F L_{t} / \mathcal{Y}_{t}$ ratio since 1980, and predict a continued rise for the next two decades.

${ }^{38}$ Indeed, the importance of news concerning future net exports discussed in Section 5.3 is consistent with the mechanism they emphasize. Since the cyclical model I estimate allows for adjustment through both the trade and valuation channels, the model allows us to quantify the combined effects of news concerning future trade flows and the SDF. In particular, Figure 5 shows that the trade and valuation channels operated in different directions on $n f l_{t}$ between 1998 and 2004, so there appear to be many factors driving the dynamics of the U.S. external position during this period.
} 
lower interest rates, so we would expect to see evidence of a secular upward trend in the SDF if it directly contributed to the persistent deterioration of the U.S. external position. There is, however, no evidence of such a trend in the SDF implied by returns (see Table 3 and Appendix). The savings glut may have contributed to the cyclical variations in the U.S. external position (via changing SDF expectations that drive the valuation channel) but it does not appear to have directly contributed to the persistent rise in $N F L_{t} / \mathcal{T}_{t}$ over the past 60 years.

\subsection{Valuation Effects}

Figure 7 provides a historical perspective on the role of the valuation effects since 1980. Panel A plots the valuation component, $\widehat{n f l}_{t}^{\kappa}$, and the VIX index (a measure of uncertainty computed from the implied volatility of options on the S\&P 500). If international investors have a preference for holding more of their wealth in dollar-denominated securities when uncertainty increases, the portfolio shift should raise $\widehat{n f l}_{t}^{\kappa}$ via capital gains on liabilities and losses on assets. Conversely, a reduction in uncertainty should lead to a fall in $\widehat{n f l}_{t}^{\kappa}$ as investors shift away from dollardenominated securities. Panel A provides limited support for these safe-haven effects. Between 1986 and 2003 the swings in valuation component and the VIX roughly coincide, but thereafter the link between the series is much less clear. In particular, the sharp rise in the VIX around the financial crisis is not matched by an increase in the valuation component consistent with the 2001-2003 period. Fogli and Perri (2015) study another measure of uncertainty from the standard deviation of GDP growth for a particular country over a 10-year window, relative to the same measure in other OECD countries. In the U.S. case, their uncertainty measure displays cycles with peaks in the early 1980's and 2000's, near those found in the valuation component.

Panel B of Figure 7 plots $\widehat{n f l}_{t}^{\kappa}$ and the yield spread, $\nabla r_{t}$. In the absence of arbitrage opportunities, the spread embeds expectations about future changes in the SDF, ${ }^{39}$ and so should have some forecasting power for future changes in $\widehat{n f l}_{t}^{\kappa}$. In particular, positive spreads should precede a fall in the valuation component, and negative spreads should precede a rise. The behavior of the valuation component and spread between 1990 and 2007 this is fairly consistent with this pattern. Thereafter the evidence is more mixed. In particular, the positive spreads since 2008 did not precede a substantial fall in the valuation component. According to my estimates, anticipated changes in $\widehat{n f l}_{t}^{\kappa}$ only account for 20 percent of the variance in actual changes over a three-year horizon. So while the spread provides a reasonably reliable indicator of future adjustment via the valuation channel when SDF expectations are stable, it is less reliable when expectations are volatile.

\footnotetext{
${ }^{39}$ To a first-order approximation, $\nabla r_{t}=-\mathbb{E}_{t} \sum_{i=2}^{n}\left(1-\frac{i-1}{n}\right) \Delta \kappa_{t+i}$.
} 
Figure 7: The Valuation Channel
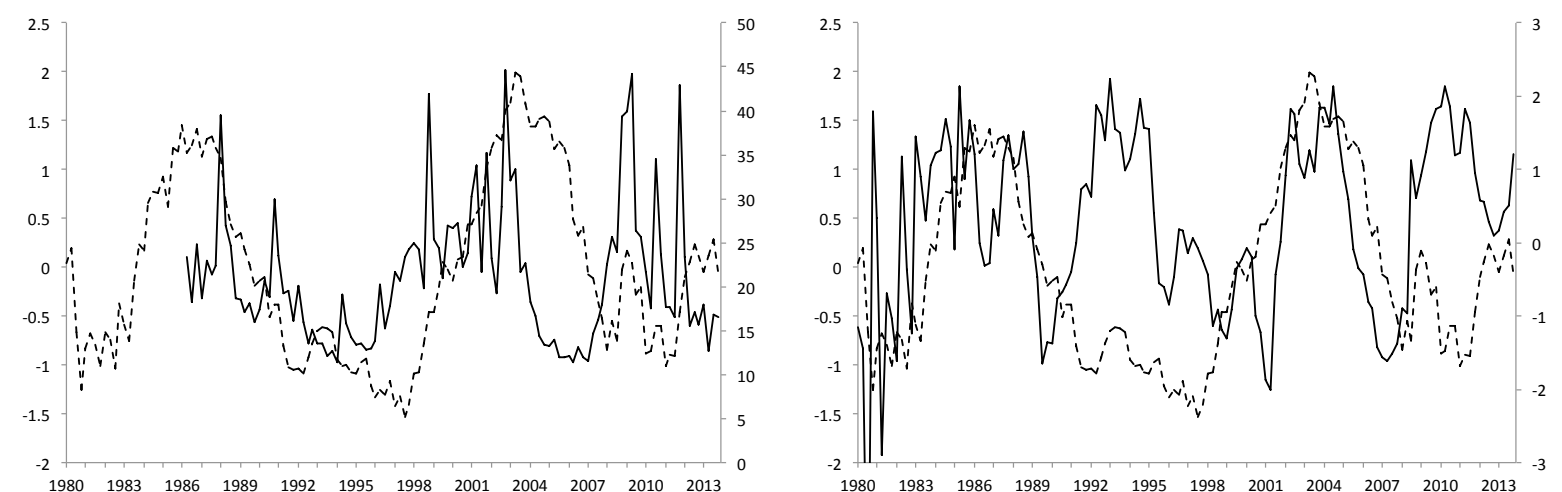

A: $V I X_{t}$ (solid: $\mathrm{RH}$ axis) and $\widehat{n f l}_{t}^{\kappa}$ (dashed: LH axis).

B: $\nabla r_{t}$ (solid: RH axis) and $\widehat{n f l} l_{t}^{\kappa}$ (dashed: LH axis)

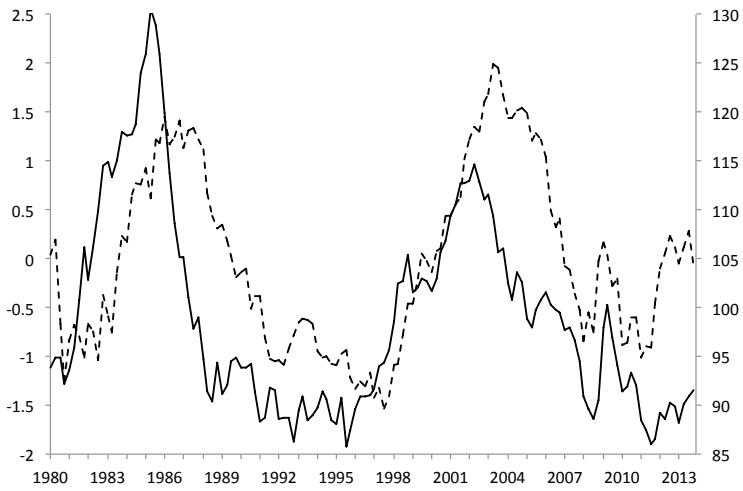

C: $\mathcal{E}$ (solid: RH axis) and $\widehat{n f l}_{t}^{\kappa}$ (dashed: LH axis)

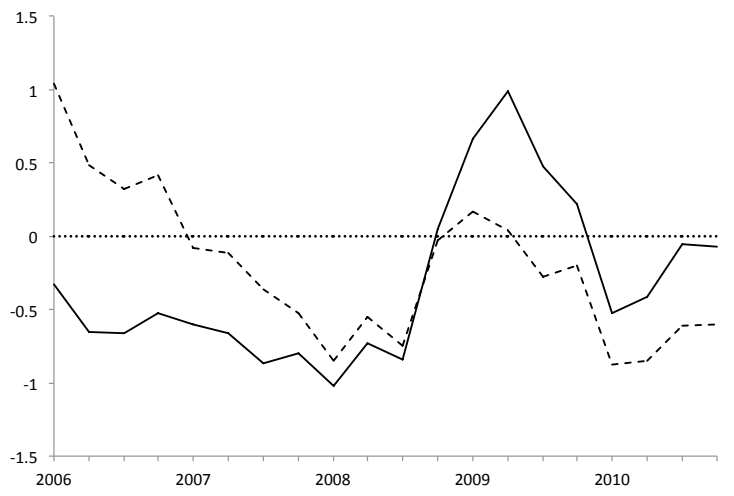

D: Cyclical $N F L_{t} / \mathcal{T}_{t}$ (solid) and $\widehat{n f l} t_{t}^{\kappa}$ (dashed)

Panel C shows the time series for $\widehat{n f l}_{t}^{\kappa}$ and the log real effective dollar exchange rate, $\ln \mathcal{E}_{t}$. Here we see that the persistent cycles in $\widehat{n f l}_{t}^{\kappa}$ are closely associated with the swings in $\ln \mathcal{E}_{t}$. To interpret this finding, consider the no-arbitrage link between real exchange rates and the difference between the foreign to the U.S. log SDFs found in Backus, Foresi, and Telmer (2001): $\ln \mathcal{E}_{t+1}-\ln \mathcal{E}_{t}=\kappa_{t+1}^{*}-\kappa_{t+1}{ }^{40}$ Rewriting this expression as a difference equation in $\ln \mathcal{E}_{t}$, solving forward and taking expectations gives $\ln \mathcal{E}_{t}=\mathbb{E}_{t} \sum_{i=1}^{\infty}\left(\kappa_{t+i}-\kappa_{t+1}^{*}\right)+\lim _{i \rightarrow \infty} \mathbb{E}_{t} \ln \mathcal{E}_{t+i}$. Clearly, then, revisions in agents' expectations concerning $\kappa_{t+i}$ produce changes in both the real exchange rate and the valuation component. Moreover, insofar as changes in $\mathbb{E}_{t} \kappa_{t+i}$ dominate those in $\mathbb{E}_{t} \kappa_{t+i}^{*}$, movements in $\ln \mathcal{E}_{t}$ and the valuation component should be strongly positively correlated. ${ }^{41}$ The high degree of coherence between $\widehat{n f l}_{t}^{\kappa}$ and $\ln \mathcal{E}_{t}$ provides further insight into the asymmetric roles played by U.S. foreign assets and liabilities in generating valuation

\footnotetext{
${ }^{40} \kappa_{t+1}^{*}$ is the log SDF that prices securities in the basket of foreign currencies used in constructing the dollar effective exchange rate.

${ }^{41}$ Interestingly, there is no strong correlation between the real exchange rate and the valuation component before 1980, suggesting that the variations in $\mathbb{E}_{t} \kappa_{t+i}^{*}$ were relatively more important earlier in the sample.
} 
adjustments. Because U.S. foreign assets are dominated in foreign currency and U.S. foreign liabilities are denominated in domestic currency, variations in dollar exchange rates produce capital gains and losses on foreign assets but not liabilities when local security prices are constant. The high degree of coherence between $\widehat{n f l}_{t}^{\kappa}$ and $\ln \mathcal{E}_{t}$ reflects the fact that capital gains and losses on foreign assets associated with real exchange rate movements account for a substantial portion of external adjustment through the valuation channel.

Finally, Panel D plots $\widehat{n f l}_{t}^{\kappa}$ and $n f l_{t}$ from 2006. According to my calculations, differences between the average returns on foreign assets and liabilities raise the steady state NFL value by approximately three percent of GDP. Gourinchas, Rey, and Govillot (2010) argue that a counterpart to this "exorbitant privilege" is an "exorbitant duty" on the part of the U.S. to transfer wealth to the rest of the world during times when their marginal utility of consumption is unusually high. Panel D shows the size of this global insurance mechanism during the world financial crisis. As the plot shows, the $n f l_{t}$ series increased from roughly -1 to +1 between 2008:I and 2009:II. This represents a wealth transfer from the U.S. equal to approximately 30 percent

of GDP. Notice, however, that the rise in $\widehat{n f l}_{t}^{\kappa}$ over the same period is roughly half as large as the rise in $n f l_{t}$. By this metric, only 50 percent of the international wealth transfer associated with the crisis is directly attributable to the valuation channel.

\section{Conclusion}

The model presented in this paper provides a new perspective on the persistent deterioration in the U.S. external position over the past 60 years. My results show that shocks working through the valuation channel have been the dominant driver of the U.S. position at cyclical frequencies. In contrast, the secular accumulation of the international debt appears to be driven via the trade channel by persistent and unprecedented optimism concerning future net exports. This dichotomy between the adjustment channels driving the secular and cyclical dynamics of the U.S. NFL position represents a challenge to existing models of international imbalances.

\section{References}

Backus, David, Thomas Cooley, and Espen Henriksen. 2014. "Demography and low-frequency capital flows." Journal of International Economics 92:S94-S102.

Backus, David, Espen Henriksen, Frederic Lambert, and Christopher Telmer. 2009. "Current Account Fact and Fiction." Working Paper 15525, National Bureau of Economic Research. 
Backus, David K., Silverio Foresi, and Chris I. Telmer. 2001. "Affine Term Structure Models and the Forward Premium Anomaly." The Journal of Finance 56 (1):279-304.

Bernanke, Ben S. 2005. "The global saving glut and the US current account deficit." Board of Governors of the Federal Reserve System (US) Speech (Mar 10).

Blanchard, Olivier and Francesco Giavazzi. 2002. "Current account deficits in the euro area: the end of the Feldstein-Horioka puzzle?" Brookings papers on economic activity 2002 (2):147-209.

Caballero, Ricardo J., Emmanuel Farhi, and Pierre-Olivier Gourinchas. 2008. "An Equilibrium Model of "Global Imbalances" and Low Interest Rates." 98 (1):358-93.

Caballero, Ricardo J and Arvind Krishnamurthy. 2009. "Global Imbalances and Financial Fragility." The American Economic Review 99 (2):584.

Campbell, John Y. and Robert J. Shiller. 1988. "The Dividend-Price Ratio and Expectations of Future Dividends and Discount Factors." Review of Financial Studies 1 (3):195-228.

Campbell, J.Y. and R.J. Shiller. 1987. "Cointegration and tests of present value models." The Journal of Political Economy 95 (5).

Cochrane, J.H. 2001. Asset Pricing. Princeton University Press.

Coeurdacier, Nicolas and Helene Rey. 2012. "Home Bias in Open Economy Financial Macroeconomics." Journal of Economic Literature 51 (1):63-115.

Corsetti, Giancarlo and Panagiotis T. Konstantinou. 2012. "What Drives US Foreign Borrowing? Evidence on the External Adjustment to Transitory and Permanent Shocks." American Economic Review 102 (2):1062-92.

Curcuru, S.E., T. Dvorak, and F.E. Warnock. 2007. "Cross-border returns differentials." Quarterly Journal of Economics .

Devereux, Michael B. and Alan Sutherland. 2010. "Country portfolio dynamics." Journal of Economic Dynamics and Control 34 (7):1325 - 1342.

Durdu, C Bora, Enrique G Mendoza, and Marco E Terrones. 2012. "On the solvency of nations: Cross-country evidence on the dynamics of external adjustment." Journal of International Money and Finance.

Engel, Charles and John H. Rogers. 2006. "The U.S. current account deficit and the expected share of world output." Journal of Monetary Economics 53 (5):1063 - 1093. 
Evans, Martin D. D. 2011. Exchange-Rate Dynamics. Princeton Series in International Finance.

- 2014. "Risk, external adjustment and capital flows." Journal of International Economics 92, Supplement 1 (0):S68 - S93.

Fogli, Alessandra and Fabrizio Perri. 2015. "Macroeconomic Volatility and External Imbalances." Working Paper 20872, National Bureau of Economic Research.

Forbes, K.J. 2009. "Why do foreigners invest in the United States?" Journal of International Economics .

Gourinchas, Pierre-Olivier and Hélène Rey. 2005. "From World Banker to World Venture Capitalist: US External Adjustment and the Exorbitant Privilege." Working Paper 11563, National Bureau of Economic Research.

Gourinchas, Pierre-Olivier. and Hélène Rey. 2007a. "International financial adjustment." Journal of Political Economy 115 (4):665-703.

Gourinchas, Pierre-Olivier and Hélene Rey. 2013. "External Adjustment, Global Imbalances, Valuation Effects." Handbook of International Economics 4.

Gourinchas, Pierre-Olivier, HéLène Rey, and Nicolas. Govillot. 2010. Exorbitant privilege and exorbitant duty. Institute for Monetary and Economic Studies, Bank of Japan.

Gourinchas, Pierre-Olivier, Hélène Rey, and Kai Truempler. 2012. "The financial crisis and the geography of wealth transfers." Journal of International Economics 88 (2):266 - 283.

Gourinchas, Pierre-Olivier.O. and Hélène Rey. 2007b. "From world banker to world venture capitalist: US external adjustment and the exorbitant privilege." G7 Current Account Imbalances: Sustainability and Adjustment. University of Chicago Press.

Habib, M.M. 2010. Excess returns on net foreign assets: The exorbitant privilege from a global perspective. European Central Bank.

Hausmann, R. and F. Sturzenegger. 2006. Global Imbalances Or Bad Accounting?: The Missing Dark Matter in the Wealth of Nations. John F. Kennedy School of Government, Harvard University.

Lane, Philip R. and Gian Maria Milesi-Ferretti. 2005. "A Global Perspective on External Positions." Working Paper 11589, National Bureau of Economic Research. 
Lane, P.R. and G.M. Milesi-Ferretti. 2009. "Where did all the borrowing go? A forensic analysis of the US external position." Journal of the Japanese and International Economies 23 (2):177199.

Meissner, Christopher M. and Alan M. Taylor. 2006. "Losing our Marbles in the New Century? The Great Rebalancing in Historical Perspective." Working Paper 12580, National Bureau of Economic Research.

Mendoza, Enrique G, Vincenzo Quadrini, and Jose-Vıctor Rıs-Rull. 2009. "Financial Integration, Financial Development, and Global Imbalances." Journal of Political Economy 117 (3).

Obstfeld, Maurice. 2012. "Does the Current Account Still Matter?" Working Paper 17877, National Bureau of Economic Research.

Obstfeld, Maurice and Kenneth Rogoff. 2007. "The unsustainable US current account position revisited." In G7 current account imbalances: Sustainability and adjustment. University of Chicago Press, 339-376.

Obstfeld, Maurice. and Kenneth S. Rogoff. 1995. "The intertemporal approach to the current account." Elsevier, 1731-1799.

_ 2005. "Global current account imbalances and exchange rate adjustments." Brookings papers on economic activity 2005 (1):67-123.

Pavlova, Anna and Roberto Rigobon. 2008. "Equilibrium portfolios and external adjustment under incomplete markets." manuscript, London Business School .

Roubini, Nouriel and Brad Setser. 2005. "The sustainability of the US external imbalances." In CESifo Forum, vol. 1. Ifo Institute for Economic Research at the University of Munich, 8-15.

Summers, Lawrence H. 2004. "The United States and the global adjustment process." Third Annual Stavros S. Niarchos Lecture. Peterson Institute for International Economics. .

Tille, Cedric. and Eric van Wincoop. 2010. "International Capital Flows." Journal of International Economics 80 (2):157-175.

White, Halbert. 1980. "A heteroskedasticity-consistent covariance matrix estimator and a direct test for heteroskedasticity." Econometrica :817-838.

Zucman, Gabriel. 2013. "The Missing Wealth of Nations: Are Europe and the U.S. net Debtors or net Creditors?*." The Quarterly Journal of Economics 128 (3):1321-1364. 


\section{Appendix (Not For Publication)}

\section{Approximation}

To derive the approximation in (10) - (12), I first rewrite (9) as

$$
\frac{N F L_{t}}{\mathcal{T}_{t}}=\mathbb{E}_{t} \sum_{i=1}^{\infty} \exp \left(\sum_{j=1}^{i} \delta_{t+j}\right)\left(\exp \left(z_{t+i}\right)-\exp \left(y_{t+i}\right)\right)
$$

where $\delta_{t}=\kappa_{t}+\Delta \tau_{t}, z_{t}=\frac{1}{2} \ln N X_{t}$ and $y_{t}=-\frac{1}{2} \ln N X_{t}$. I then take a first-order approximation around the point where $\delta_{t}=\delta, z_{t}=z$ and $y_{t}=y$. This gives

$$
\begin{gathered}
\frac{N F L_{t}}{\mathcal{T}_{t}}=\mathbb{E}_{t} \exp \left(\delta_{t+1}\right)\left(\exp \left(z_{t+1}\right)-\exp \left(y_{t+1}\right)\right)+\mathbb{E}_{t} \exp \left(\delta_{t+1}+\delta_{t+2}\right)\left(\exp \left(z_{t+2}\right)-\exp \left(y_{t+2}\right)\right)+\ldots \\
\cong \frac{\rho(Z-Y)}{1-\rho}+(Z-Y)\left\{\rho+\rho^{2}+\rho^{3}+\ldots\right\}\left(\delta_{t+1}-\delta\right) \\
+(Z-Y)\left\{\rho^{2}+\rho^{3}+\ldots\right\}\left(\delta_{t+2}-\delta\right)+\ldots \\
+Z \rho\left(z_{t+1}-z\right)+Z \rho^{2}\left(z_{t+2}-z\right)+. . \\
-Y \rho\left(y_{t+1}-y\right)-Y \rho^{2}\left(y_{t+2}-y\right)-. . \\
=\mathbb{E}_{t}\left\{\frac{\rho(Z-Y)}{1-\rho}+\frac{(Z-Y)}{1-\rho} \sum_{i=1}^{\infty} \rho^{i}\left(\delta_{t+i}-\delta\right)+\sum_{i=1}^{\infty} \rho^{i}\left\{Z\left(z_{t+i}-z\right)-Y\left(y_{t+i}-y\right)\right\}\right\}
\end{gathered}
$$

where $\rho=\exp (\delta) Z=\exp (z)$ and $Y=\exp (y)$. Substituting the original variables into this expression gives the approximation in (10) - (12).

\section{Current Account Equation}

I derive the current account equation (7) by combining (5) with the identity $C A_{t}=-\mathbb{E}_{t-1} \Delta N F L_{t}-$ $\left(N F L_{t}-\mathbb{E}_{t-1} N F L_{t}\right)$. The first term on the right is computed from (5) as follows. First, I iterate (5) one period forward, to get

$$
N F L_{t}=\mathbb{E}_{t}\left[\mathcal{K}_{t+1}\left(X_{t+1}-M_{t+1}\right)\right]+\mathbb{E}_{t}\left[\mathcal{K}_{t+1} N F L_{t+1}\right]
$$

Rearranging this expression gives

$$
-\mathbb{E}_{t} \Delta N F L_{t+1}=\frac{1}{\mathbb{E}_{t} \mathcal{K}_{t+1}}\left\{\mathbb{E}_{t}\left[\mathcal{K}_{t+1}\left(X_{t+1}-M_{t+1}\right)\right]-\left(1-\mathbb{E}_{t} \mathcal{K}_{t+1}\right) N F L_{t}+\mathbb{C V}_{t}\left(\mathcal{K}_{t+1}, N F L_{t+1}\right)\right\}
$$


Lagging this equation one period, and substituting the result for $-\mathbb{E}_{t-1} \Delta N F L_{t}$ in the current account identity above gives

$C A_{t}=\frac{1}{\mathbb{E}_{t-1} \mathcal{K}_{t}}\left\{\mathbb{E}_{t-1}\left[\mathcal{K}_{t}\left(X_{t}-M_{t}\right)\right]-\left(1-\mathbb{E}_{t-1} \mathcal{K}_{t}\right) N F L_{t-1}+\mathbb{C V}_{t-1}\left(\mathcal{K}_{t}, N F L_{t}\right)\right\}-\left(N F L_{t}-\mathbb{E}_{t-1} N F L_{t}\right)$

Finally I substitute for $N F L_{t}$ from (5) to give

$$
\begin{aligned}
C A_{t}=\mathbb{E}_{t-1} & \left\{\mathcal{K}_{t}\left(X_{t}-M_{t}\right)-\left(1-\mathcal{K}_{t}\right) \sum_{i=1}^{\infty} \mathcal{K}_{t+i}^{(i)}\left(X_{t-1+i}-M_{t-1+i}\right)\right\}\left(\mathbb{E}_{t-1} \mathcal{K}_{t}\right)^{-1} \\
+ & \mathbb{C V}_{t-1}\left(\mathcal{K}_{t}, N F L_{t}\right)\left(\mathbb{E}_{t-1} \mathcal{K}_{t}\right)^{-1}-\left(\mathbb{E}_{t}-\mathbb{E}_{t-1}\right) \sum_{i=1}^{\infty} \mathcal{K}_{t+i}^{(i)}\left(X_{t+i}-M_{t+i}\right),
\end{aligned}
$$

which is equation $(7)$.

\section{Additional Empirical Results}

Table 8 reports Augmented Dickey Fuller tests for the null of a unit root in selected variables. All tests allow for the presence of a constant and a time trend. The the right hand column reports the number of lags of the dependent variable included in the test regression (chosen using the general-to-specific testing procedure).

Table 8: ADF Unit Root Tests

\begin{tabular}{lllc}
\hline Variable & Statistic & p-value & lags \\
\hline$N F L_{t} / \mathcal{T}_{t}$ & -3.649 & 0.059 & 6 \\
$\ln (N X)$ & -3.258 & 0.073 & 4 \\
$F L_{t} / \mathcal{T}_{t}$ & -1.159 & 0.917 & 6 \\
$F A_{t} / \mathcal{T}_{t}$ & -1.838 & 0.686 & 6 \\
\hline
\end{tabular}

Figure 8 plots the time series of the estimated log SDFs. Consistent with the visual evidence in this plot, regressions of the log SDFs on a time trend produce economically and statistically insignificant coefficients. There is no discernible trend in either time series. 
Figure 8: Estimated SDFs

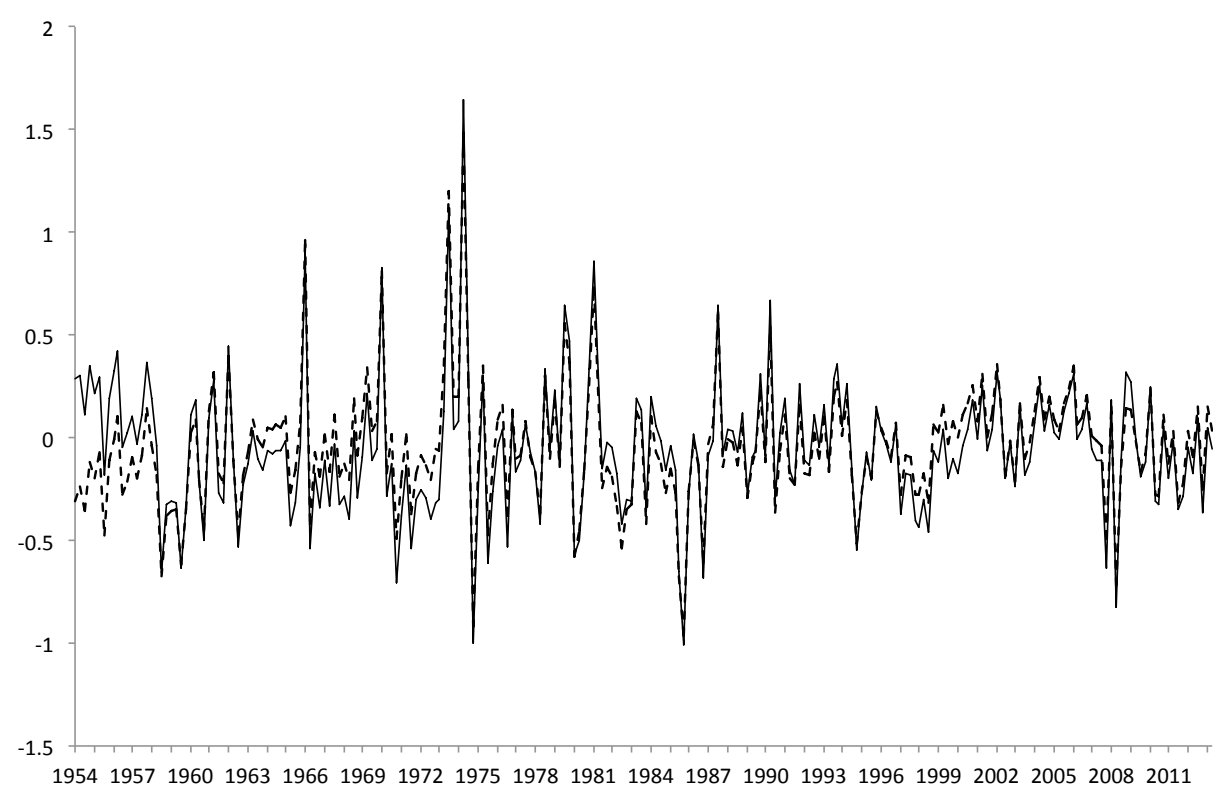

Time series for $\hat{\kappa}_{t}^{\mathrm{II}}$ (solid) and $\hat{\kappa}_{t}^{\mathrm{I}}$ (dashed).

Table 9 reports the results of Granger Causality tests computed from second- and third-order VARs for $\kappa_{t}, \Delta \tau_{t}, n x_{t}$ and $n f l_{t}$. Each entry shows the test statistic and asymptotic p-value for the null hypothesis that the variable listed at the left-hand-end of each row does not Granger Cause the variable listed at the head of each column. The table reveals three noteworthy features of the data. First we can reject the null of no Granger Causality for at least one variable in each forecasting equation. Thus, to some degree, all the variables are forecastable. Second there is no statistically significant evidence that the cyclical component in $N F L_{t} / \mathcal{T}_{t}, n f l_{t}$, Granger Causes either the $\log \mathrm{SDF}, \kappa_{t}$, or the net export ratio, $n x_{t}$. One interpretation of this result is that agents' expectations concerning the future behavior of $\kappa_{t}$ and $n x_{t}$ are adequately represented by the time series forecasts for these variables conditioned only on their past histories. However, the present value restrictions in (12) imply that $n f l_{t}$ reflects agents' expectations about the entire future paths for $\kappa_{t}$ and $n x_{t}$. As such, $n f l_{t}$ may not have a significant degree of incremental forecasting power for either variable one quarter ahead, while still reflecting agents' private information about the future path of each variable. The third feature concerns the forecasting power of $n f l_{t}$. As the right-hand column of the table shows, both $\kappa_{t}$ and $\Delta \tau_{t}$ appear to strongly Granger Cause $n f l_{t}$. Section 2.3 showed that this pattern can arise when agents' expectations for the future paths of $\kappa_{t}, \Delta \tau_{t}$, and $n x_{t}$ differ from the forecast paths based solely on the history of these variables.

Table 10 reports the variance contributions of the components $\widehat{n f l}_{t}^{j}$ estimated from a second- 
Table 9: Granger Causality

\begin{tabular}{|c|c|c|c|c|}
\hline \multirow[b]{2}{*}{ Forecasting Variables } & \multicolumn{4}{|c|}{ Forecast Variables } \\
\hline & $\kappa_{t}$ & $\Delta \tau_{t}$ & $n x_{t}$ & $n f l_{t}$ \\
\hline \multicolumn{5}{|l|}{$\mathrm{A}: \operatorname{VAR}(2)$} \\
\hline \multirow[t]{2}{*}{$\kappa_{t}$} & 10.152 & 1.459 & 1.407 & 7.454 \\
\hline & $(0.006)$ & $(0.482)$ & $(0.495)$ & $(0.024)$ \\
\hline \multirow[t]{2}{*}{$\Delta \tau_{t}$} & 1.309 & 4.572 & 13.555 & 12.216 \\
\hline & $(0.520)$ & $(0.102)$ & $(0.001)$ & $(0.002)$ \\
\hline \multirow[t]{2}{*}{$n x_{t}$} & 0.455 & 4.506 & 2224.414 & 0.178 \\
\hline & $(0.796)$ & $(0.105)$ & $(0.000)$ & $(0.915)$ \\
\hline \multirow[t]{2}{*}{$n f l_{t}$} & 2.700 & 11.688 & 3.048 & 790.202 \\
\hline & $(0.259)$ & $(0.003)$ & $(0.218)$ & $(0.000)$ \\
\hline \multicolumn{5}{|l|}{ B: $\operatorname{Var}(3)$} \\
\hline \multirow[t]{2}{*}{$\kappa_{t}$} & 12.954 & 4.317 & 2.624 & 8.978 \\
\hline & $(0.005)$ & $(0.229)$ & $(0.453)$ & $(0.030)$ \\
\hline \multirow[t]{2}{*}{$\Delta \tau_{t}$} & 1.155 & 4.667 & 11.346 & 13.295 \\
\hline & $(0.764)$ & $(0.198)$ & $(0.010)$ & $(0.004)$ \\
\hline \multirow[t]{2}{*}{$n x_{t}$} & 12.787 & 5.359 & 2292.640 & 2.406 \\
\hline & $(0.005)$ & $(0.147)$ & $(0.000)$ & $(0.492)$ \\
\hline \multirow[t]{2}{*}{$n f l_{t}$} & 2.164 & 12.811 & 5.943 & 897.784 \\
\hline & $(0.539)$ & $(0.005)$ & $(0.114)$ & $(0.000)$ \\
\hline
\end{tabular}

Notes: The table reports $\chi^{2}$ statistics and asymptotic p-values in parenthesis for the null that that lags of the forecasting variable shown in each row do not Granger Cause the forecast variable listed at the head of each column.

and third-order VAR (without the cross-equation restrictions). 
Table 10: Variance Decompositions from VARs

\begin{tabular}{|c|c|c|c|c|}
\hline \multicolumn{2}{|l|}{ Model } & Variance & \multicolumn{2}{|c|}{ 95\% Confidence Band } \\
\hline \multicolumn{5}{|l|}{$\operatorname{VAR}(2)$} \\
\hline & $\widehat{n f l} l_{t}^{\kappa}+\widehat{n f l}_{t}^{n x}+\widehat{n f l}_{t}^{\Delta \tau}$ & 0.972 & {$[0.695$} & $1.250]$ \\
\hline & $\widehat{n f l} l_{t}^{\kappa}$ & 0.448 & {$[0.427$} & $0.468]$ \\
\hline & $\widehat{n f l}_{t}^{n x}+\widehat{n f l}_{t}^{\Delta \tau}$ & 0.525 & 0.250 & 0.799] \\
\hline & $\widehat{n f l} l_{t}^{n x}$ & 0.494 & 0.217 & $0.770]$ \\
\hline & $\widehat{n f l}_{t}^{\Delta \tau}$ & 0.031 & {$[0.027$} & $0.036]$ \\
\hline \multicolumn{5}{|l|}{$\operatorname{VAR}(3)$} \\
\hline & $\widehat{n f l} l_{t}^{\kappa}+\widehat{n f l} l_{t}^{n x}+\widehat{n f l} l_{t}^{\Delta \tau}$ & 1.487 & {$[1.247$} & $1.727]$ \\
\hline & $\widehat{n f l} l_{t}^{\kappa}$ & 1.019 & {$[0.927$} & $1.110]$ \\
\hline & $\widehat{n f l}_{t}^{n x}+\widehat{n f l}_{t}^{\Delta \tau}$ & 0.468 & 0.196 & $0.740]$ \\
\hline & $\widehat{n f l} l_{t}^{n x}$ & 0.381 & {$[0.105$} & $0.657]$ \\
\hline & $\widehat{n f l}_{t}^{\Delta \tau}$ & 0.087 & 0.076 & $0.099]$ \\
\hline
\end{tabular}

Notes: The table reports the variance contributions of the estimated valuation and trade components computed from a second- and third-order VAR, together with the 95 percent confidence band. 